\title{
Mesenchymal stem cell carriers enhance antitumor efficacy of oncolytic adenoviruses in an immunocompetent mouse model
}

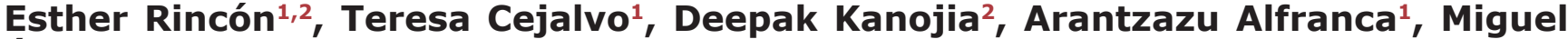 \\ Ángel Rodríguez-Milla ${ }^{1}$, Raul Andrés Gil Hoyos ${ }^{3}$, Yu Han'2, Lingjiao Zhang ${ }^{2}$, Ramón \\ Alemany $^{3}$, Maciej S. Lesniak ${ }^{2}$ and Javier García-Castro ${ }^{1}$ \\ ${ }^{1}$ Unidad de Biotecnología Celular, Instituto de Salud Carlos III, Madrid, Spain \\ ${ }^{2}$ The Brain Tumor Center, The University of Chicago, Chicago, Illinois, USA \\ ${ }^{3}$ Institut Català d'Oncologia, IDIBELL, Barcelona, Spain \\ Correspondence to: Javier García-Castro, email: jgcastro@isciii.es
}

Keywords: mesenchymal stem cells, carriers, oncolytic adenoviruses, immunotherapy, cancer

Received: July 28, $2016 \quad$ Accepted: April 18, $2017 \quad$ Published: May 02, 2017

Copyright: Rincón et al. This is an open-access article distributed under the terms of the Creative Commons Attribution License 3.0 (CC BY $3.0)$, which permits unrestricted use, distribution, and reproduction in any medium, provided the original author and source are credited.

\section{ABSTRACT}

Oncolytic virotherapy represents a promising alternative for cancer treatment; however, viral delivery to the tumor represents a major challenge. Mesenchymal stem cells (MSCs) chemotax to tumors, and can serve as a viral delivery tool. Previously, we demonstrated antitumor therapeutic efficacy for mesenchymal stem cells (MSCs) infected with the oncolytic human adenovirus ICOVIR5 (Celyvir) for treatment of neuroblastoma patients. Given the lack of suitable immunocompetent preclinical models, the mechanism underlying Celyvir antitumor activity remains unknown. In this study, we used the syngeneic murine CMT64 cell line as a human adenovirussemi-permissive tumor model and demonstrate the homing capacity of mouse Celyvir (mCelyvir) to CMT64 tumors. We found that the combined treatment of mCelyvir and intratumoral injections (i.t.) of ICOVIR5 was more effective than treatment with i.t. ICOVIR5 alone. Interestingly, the superior therapeutic effect of the combined therapy was associated with a higher tumor infiltration of CD8+ and CD4+ T cells. Our findings suggest that the use of MSCs as carriers of oncolytic adenovirus can improve the clinical efficacy of anti-cancer virotherapy, not only by driving the adenovirus to tumors, but also through their potential to recruit $T$ cells.

\section{INTRODUCTION}

A correlation between the level of immune cell infiltration and the clinical outcome has been detected in many cancers [1]. While antitumor immunotherapy has primarily focused on activating $\mathrm{T}$ cells and inhibiting immune checkpoints [2], oncolytic viruses may represent an alternative strategy for cytoreduction of tumors. Not only do oncolytic viruses combat tumors via direct lysis and/or vascular attack, but they also potently activate the adaptive and innate immune responses [3]. In fact, oncolytic therapy is generally thought as an immunotherapy and the term 'oncolytic immunotherapy' has been widely adopted [4].

Among oncolytic viruses used in clinical trials, oncolytic adenoviruses (Ad) present several unique characteristics, including relatively simple genetic modification for tumor selectivity, and high viral titer production [5]. Unfortunately, the efficacy of Ad-induced tumor reduction has been limited in clinical trials due to insufficient viral delivery to the tumor, and because the virus triggers the immune response that attenuates viral production [6]. Mesenchymal stem cells (MSCs) have the intrinsic capability to migrate to solid tumor and have been employed to deliver anti-cancer agents, including oncolytic Ad, specifically to the tumor. This method reduces systemic side effects, and promotes effective local anti-tumor activity. [7-9]. In addition, the ability of MSCs to modulate the immune system has been suggested to be crucial for their benefits in antitumor strategies [10-13].

Our groups have been using MSCs as delivery vehicles to improve oncolytic Ad delivery. We have previously demonstrated their potential benefits in human 
glioma xenografts in immunodeficient mice $[14,15]$, in a semi-permissive cotton rat model [10], and in the treatment of patients with metastatic neuroblastoma $[12,16]$. In humans, patients who responded to this therapy had significantly higher counts of absolute numbers and a different kinetics of circulating $\mathrm{T}$ lymphocytes during treatment, suggesting a main role of immune system in clinical responses $[12,16]$. However, a major limitation in the field is the lack of immune- and replication-competent models that are necessary to elucidate the mechanisms underpinning MSC-delivered, oncolytic Ad antitumor therapy. Given this limitation, in this study we have used a semi-permissive mouse model to study key immune system components that can be modulated to improve the therapy, and thereby improve the survival of patients with metastatic tumors. The development of an immunocompetent model has been hampered by the fact that most mouse cells do not support the replication of human $\mathrm{Ad}[17,18]$. However, murine lung carcinoma cell lines CMT64 and KLN205 support the complete replication cycle of human Ad [19-21]. In this regard, the potential benefits of using MSCs as a carrier for oncolytic Ad in these models have not been evaluated.

The present study aimed to understand the immune mechanisms involved in the antitumor therapeutic efficacy of the treatment with oncolytic Ad delivered using MSCs as vehicles. We have used the semi-permissive CMT64 cell line, syngeneic for C57BL/6 mice, as a replicationcompetent model to analyze the efficacy of murine MSCs (mMSCs) infected with the human oncolytic Ad ICOVIR5 (mCelyvir) [22, 23], as cell carriers of this Ad. ICOVIR5 replicated and induced cytopathic effect in CMT64 cells. Combined in vivo treatment with mCelyvir and ICOVIR5 intratumoral injections (i.t.) shrank tumors by $50 \%$, a higher decrease than tumors treated only with ICOVIR5 (i.t.). Interestingly, the superior therapeutic effect of combined mCelyvir and ICOVIR5 was associated with a higher tumor infiltration of CD8+ and CD4+ T lymphocytes, suggesting a main role of immune system in efficacy of Celyvir.

\section{RESULTS}

\section{Replication and cytotoxicity of ICOVIR5 in mouse CMT64 cells and mMSCs}

The murine non-small-cell lung carcinoma cell line CMT64 had been described to be semi-permissive to human Ad infection [19]. This data led us to hypothesize that some cells were producing virus while other cells were not, possibly due to heterogeneity in Ad life cycle. To avoid possible heterogeneity problems in virus production by the parental CMT64 cells, we isolated 30 different CMT64 clones by single cell isolation in 96 well plates and measured virus production in these clones (Supplementary Figure 1A). Among them, clone 6 (CMT64-6) was selected as it produced 5 to $10 \mathrm{TU} /$ cell (Figure 1A, Supplementary Figure 1A). The higher production of
Ad in CMT64-6 compared to the parental CMT64 cells could be caused by a better infectivity of this clone. To test this possibility, CMT64 parental and clone 6 were infected with AdTL, an E1- and E3-deleted recombinant serotype $5 \mathrm{Ad}$ that contains a green fluorescence protein (EGFP) and luciferase gene-expression cassette [24, 25]. The percentage of transduced cells was analyzed by fluorescence microscopy. The results indicated that when infected at an MOI of $50 \mathrm{TU} /$ cell, almost $100 \%$ of the cells of clone 6 were transduced compared to $20 \%$ infection of the parental cells (Supplementary Figure 1B).

We therefore decided to use CMT64-6 for further experiments. To measure viral replication, adenoviral E4A gene copies were quantified $72 \mathrm{~h}$ after ICOVIR5 infection (Figure 1B). The level of ICOVIR5 replication in CMT64-6 cells in this assay was approximately 5-fold lower than that detected in human HEK293 cells, a highly permissive human cell line of reference. We evaluated ICOVIR5 viral production in CMT64-6 cells compared to other cell lines, and observed that this cell line produces some ICOVIR5, but non-permissive cells, like the murine melanoma cell line B16 or mMSCs, failed to produce any Ad (Figure 1C). ICOVIR5 production yield in CMT64-6 cells was lower than the one observed in highly permissive cells, as HEK293 and human MSCs (Figure 1C). A clear cytopathic effect in culture was also detected on CMT64-6 cells, similar to that observed in human HEK293 cells. That effect was not observed in B16 cells (Figure 1D). These results indicate that CMT64-6 cells represent a mouse tumor model semi-permissive to human $\mathrm{Ad}$ ICOVIR5 replication. By contrast, mMSCs obtained from adipose tissue [26] (Supplementary Figure 2), were not able to amplify the ICOVIR5 genome (Figure 1B, 1C), even though the transduction efficiency of these cells infected with AdTL was higher than 90\% (Supplementary Figure 1C). Accordingly, we did not observe cytopathic effects in mMSC compared to human MSC (Figure 2A). These results were further confirmed using ICOVIR15Luc (a human ICOVIR5 derivative, expressing the Fireflyluciferase as an additional splicing unit of the major late promoter), which allows correlation of luciferase activity with Ad replication. As expected, luciferase activity was detected only in ICOVIR15Luc-infected human MSCs. The same results were obtained by western blot using an antiLuciferase antibody (Figure 2B). While mMSCs were not replicating virus, their population was still reduced after $\mathrm{Ad}$ infection (Figure 2C) due to apoptosis (Figure 2D). These findings indicate that, although human Ad does not replicate in mMSCs, it is still toxic for these cells.

\section{CMT64-6 cell tumors induce homing of mCelyvir}

In order to validate CMT64-6 cells as a tumor model to analyze mCelyvir efficacy, we next checked whether these stem cells are able to home to CMT64-6 cells. We first 
performed in vitro transwell migration assays to evaluate the migration ability of mMSC. Interestingly, migration of ICOVIR5-infected mMSC cells (mCelyvir) to CMT64-6 cells was similar to that shown by uninfected mMSCs at 6 and 24 hours (Figure 3A). We also analyzed if mMSCs/ mCelyvir migrate regardless of the cell type present in the bottom chamber. mMSCs/mCelyvir migrate towards mouse tumor cells (CMT64-6, RENCA and B16 cells) and primary fibroblast (MEFs), but the number of migrated mMSCs/mCelyvir depends specifically on target cell type. (Supplementary Figure 3). Our in vitro data indicate that $\mathrm{mMSC} / \mathrm{mCelyvir}$ actively migrate toward CMT64-6 cells.
To assess the in vivo migration capacity of mMSCs/ mCelyvir towards CMT64-6 tumors, we established subcutaneous tumors of CMT64-6 cells lentivirallytransduced with F-luciferase (CMT64-6Luc/GFP cells) in C57BL/6 mice. Eleven days after tumor cell inoculation, $\mathrm{mMSCs} / \mathrm{mCelyvir}$ were stained with the fluorescent dye DiR and intraperitonally (i.p.) injected into these mice. A portion of mMSCs and mCelyvir were analyzed by flow cytometry to confirm equivalent DiR staining before injection (Figure 3B). The in vivo homing of mMSCs/ mCelyvir to tumors was monitored at 4,24 , and $48 \mathrm{~h}$ postinjection to obtain serial fluorescence images using the
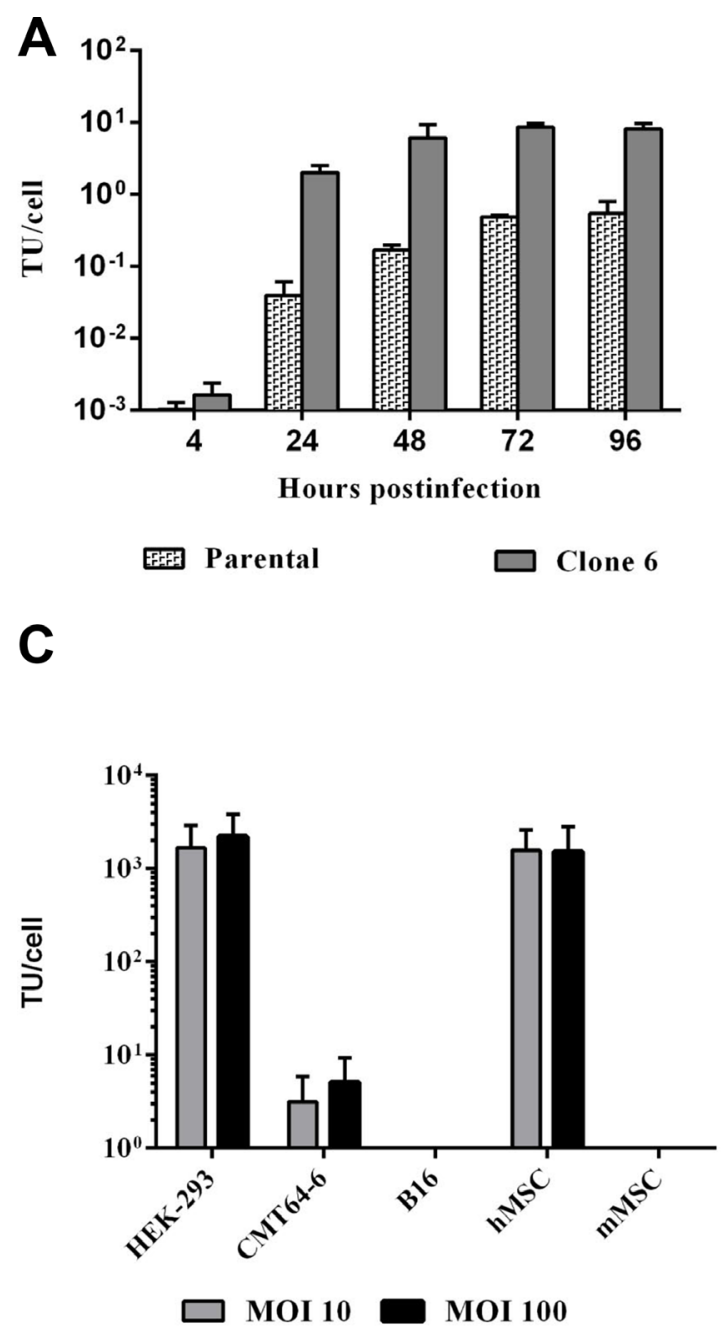

B

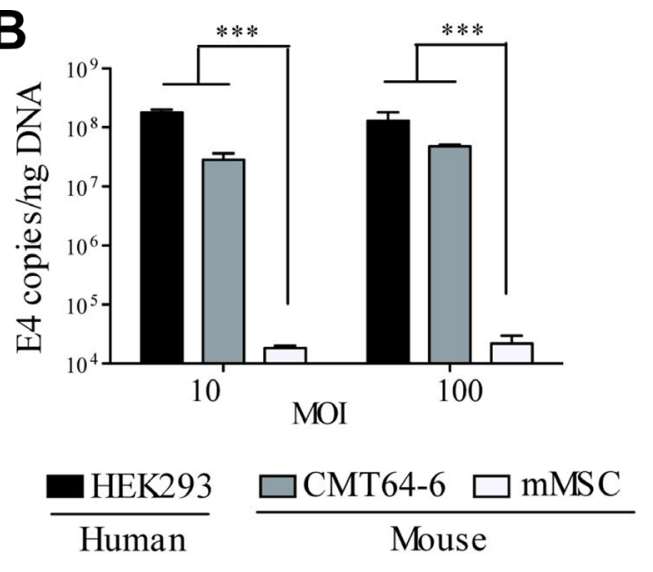

D
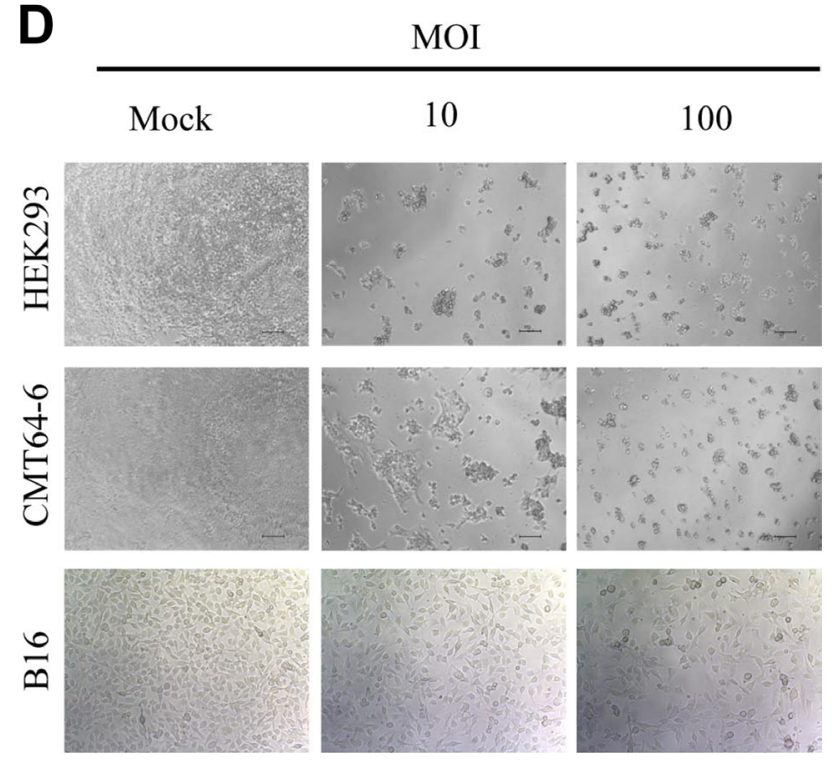

Figure 1: The murine CMT64-6 cell line supports replication of the human adenovirus ICOVIR5. (A) CMT64 parental cells and CMT64-6 clone cells were infected with human oncolytic adenovirus at MOI 200 during 4 hours. Cellular extracts were obtained at 4, 24, 48, 72 and $96 \mathrm{~h}$ and the amount of virus produced was determined by hexonprotein staining using the Adeno-X Rapid Titer Kit protocol. Bars represent mean \pm SEM. (B) Quantitative PCR detection of viral replication. HEK293, CMT64-6 cells and mMSCs were infected as previously and, 3 days post-infection, the degree of viral genome amplification was assessed by measuring the number of viral E4A copy/ ng DNA. Bars represent mean of triplicates \pm SEM. ANOVA was performed and statistical significance was defined as $* * * P<0.001$. (C) HEK-293, CMT64-6, B16, hMSC and mMSC viral production ability was evaluated. Cells were infected with ICOVIR5 at 10 and 100 MOI and, after $72 \mathrm{~h}$, cellular extracts were obtained to determine virus production as in Figure 1a. (D) HEK293 cells (as human permissive cells, positive control), CMT64-6 cells, and B16 cells (as non-permissive murine cells, negative control) were infected with different MOIs (10 and 100 infection unit/cell) and cytopathic effect was evaluated after $72 \mathrm{~h}$. Each experiment was performed at least 3 times. 
IVIS system. The highest level of homing was consistently found in tumors at 24 hours for both mMSCs and mCelyvir (Figure 3C). There were no significant differences between mMSCs and mCelyvir homing to tumors. Interestingly, DiR positive cells were also detected in other organs related with immune activation, such as spleen and lymph nodes, although the presence in those organs was generally at lower levels than in tumors (Figure 3D). The presence of DiR-stained mMSC or mCelyvir inside tumors was confirmed by confocal microscopy (Figure 3E).

\section{In vivo mCelyvir inhibit the growth of CMT64-6 tumors}

To assay the therapeutic effect of mCelyvir, we established subcutaneous tumors of CMT64-6 cells in both right and left flanks of syngeneic C57BL/6 mice. We compared groups of mice treated i.p. with PBS or mCelyvir and, given the fact that mMSCs do not support the replication of human $\mathrm{Ad}$, another group of mice were treated with Celyvir i.p. and two days later tumors were injected with saline or ICOVIR5, in order to mimic the dissemination of Ad into the tumors after infected mMSC inoculation [27]. Only tumors of the right flank were injected so the systemic therapeutic effect in the contralateral non-injected left tumor could be evaluated (Figure 4A).

Tumors were measured every three days and volume was calculated. We observed a similar tumor growth inhibition in ICOVIR5 and mCelyvir groups (30\%) compared to PBS group, and a higher inhibition in the mCelyvir-ICOVIR5 group (50\%) (Figure 4B, 4C).
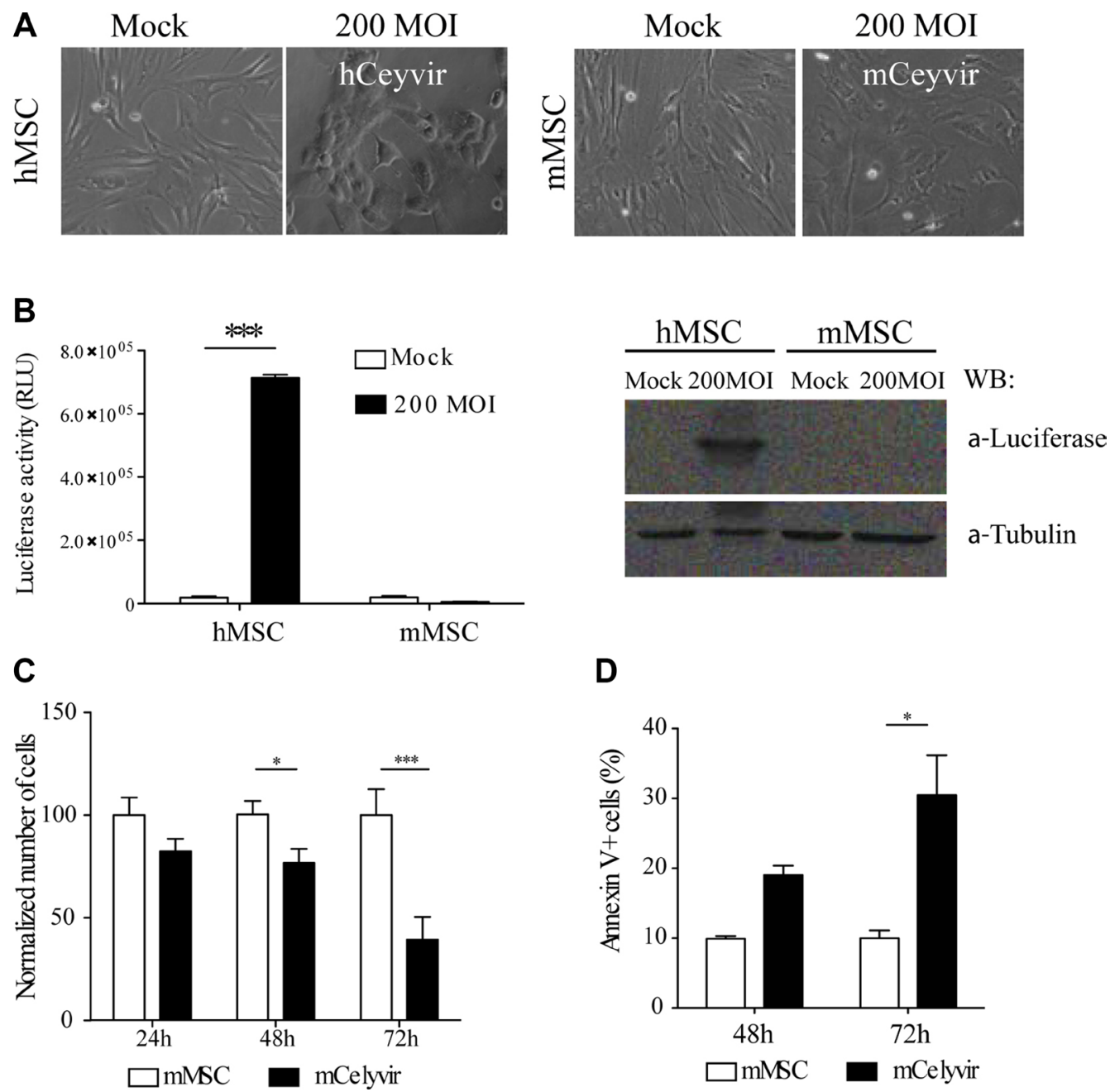

Figure 2: Permissiveness of mesenchymal stem cells to ICOVIR5. (A) hMSCs and mMSCs were infected with ICOVIR15Luc Ad at $200 \mathrm{MOI}$ and the morphology of both cell types was evaluated after $48 \mathrm{~h}$. (B) The pellets of the cells previously evaluated were lysated and luciferase activity was measured, as a readout of Ad replication. The protein expression of luciferase was also analyzed by western blot in those lysates. (C) mMSCs viability was compared to mCelyvir viability (mMSCs infected with 200 infection unit/cell of ICOVIR5) by trypan blue exclusion method, at the indicated time points after infection. The number of cells is shown as fold change compared to $100 \%$ for the non-infected cells. (D) Apoptosis cell death associated with ICOVIR5 infection was evaluated in mMSCs, $48 \mathrm{~h}$ and $72 \mathrm{~h}$ after infection. The percentage of apoptotic Annexin V+ analyzed by FACS is represented. Bars represent mean of triplicates \pm SEM. Student's $t$ test was performed and statistical significance was defined as $* P<0.05, * * P<0.01$ and $* * * P<0.001$. 

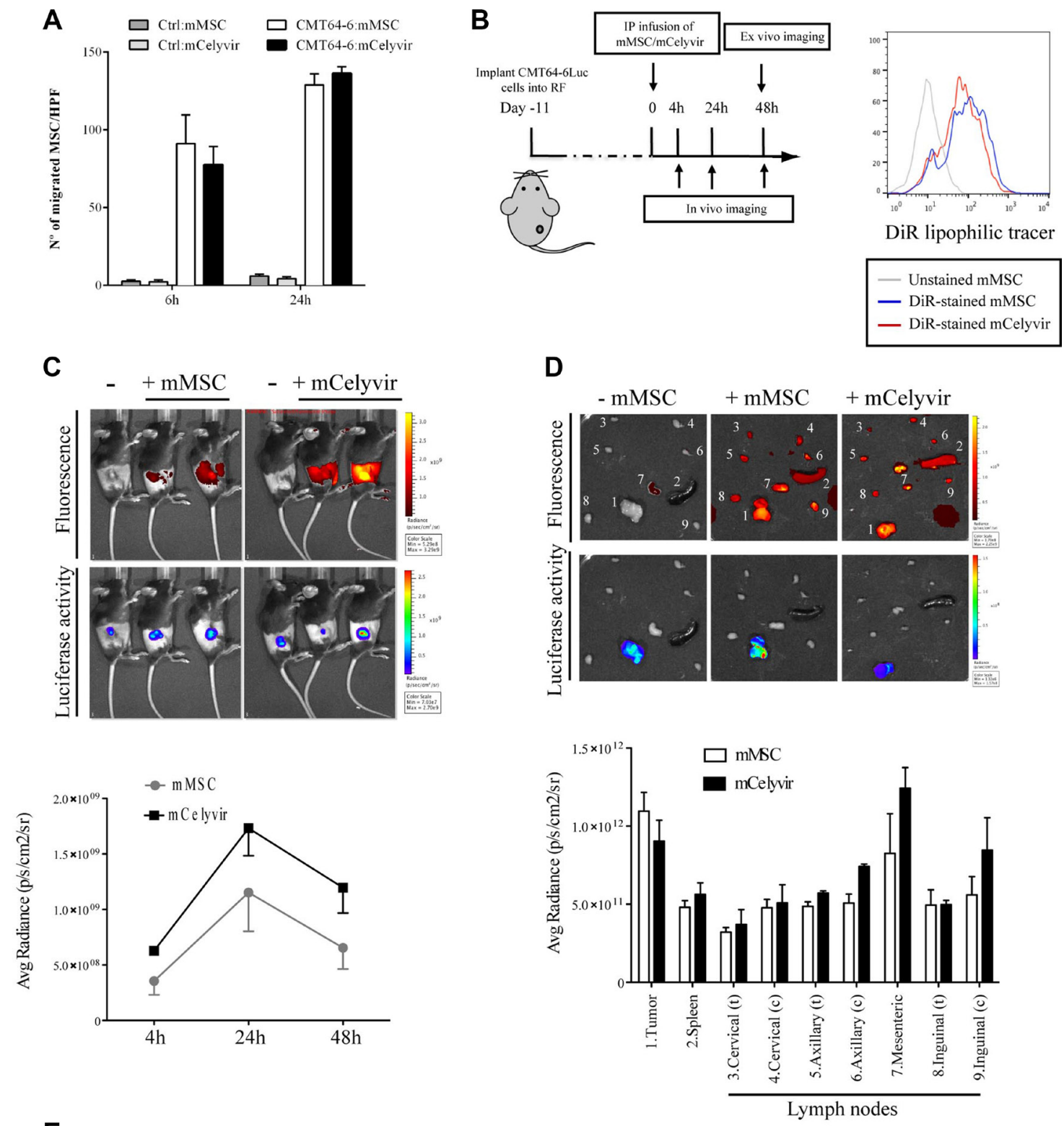

E
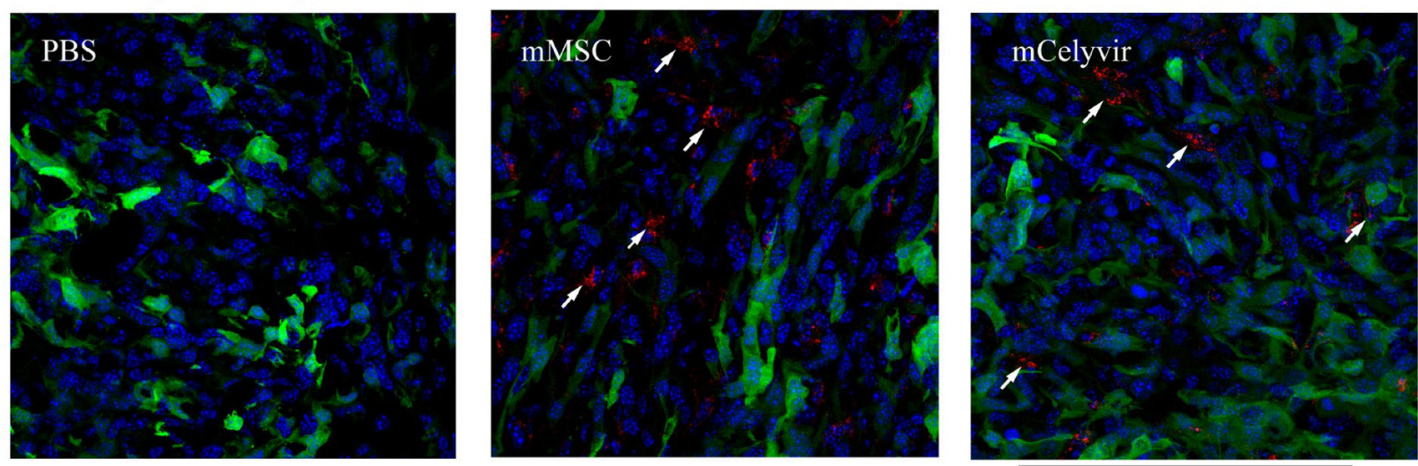

DiR-stained mCelyvir
CMT64-6Luc DAPI

Figure 3: Homing of $\mathbf{m M S C} / \mathrm{mCelyvir}$ to CMT64-6 tumors. (A) In vitro cell migration assays of mMSCs/mCelyvir against CMT64-6 cells were performed using transwells with $8 \mu \mathrm{m}$ pore filters. mMSCs/mCelyvir were transferred to the upper chambers. Cells were incubated in the presence of CMT64-6 cells in the bottom chambers, or DMEM (as negative control), for $6 \mathrm{~h}$ or $24 \mathrm{~h}$. Migrated cells were fixed, stained with crystal violet and manually counted. The graph shows the average number of migrated $\mathrm{mMSCs} / \mathrm{mCelyvir}$ 
cells in 10 HPF (high-power field). Bars represent mean of triplicates \pm SEM. (B) In vivo experiment scheme (left): CMT64-6Luc cells were implanted in the right flanks of mice. After 11 days, mMSCs or mCelyvir previously stained with fluorescence tracker DiR were i.p. infused. The homing of mMSCs/mCelyvir to tumors was monitored at 4,24 and 48 hours post-injection of mMSCs/mCelyvir to obtain serial fluorescence images. For visualizing CMT64-6Luc tumors, mice were intravenously injected with luciferin 3 minutes before imaging. In the time point $48 \mathrm{~h}$, the mice were sacrificed and ex vivo imaging of tumors, spleen and lymph nodes was performed. Both, the fluorescent and bioluminescent imaging analysis were conducted with the IVIS 200 in vivo imaging system. In the right panel it is shown the analysis by FACS of the staining of mMCSc and mCelyvir with DiR. X-axes represent fluorescence intensity; grey line is from nonstained mMSC. (C) The upper panel shows in vivo fluorescence images of DiR labeled-mMSCs or DiR labeled-mCelyvir and the lower panel bioluminescence luciferase activity images of CMT64-6Luc cells $24 \mathrm{~h}$ post-mMSC infusion. As negative control for fluorescence we used mice non-infused with mMSCs. The images are from a representative experiment. In the graph it is represented the average radiant efficiency of fluorescence values, which indicates that DiR-mMSCs accumulated in the tumor tissues and reached peak value at $24 \mathrm{~h}$ postinjection. Experiment was repeated 3 times ( $n=6$ mice per group each time) and the graph is representative of one of them. (D) Ex vivo fluorescence images of dissected organs and tumors in the control mouse and DiR-mMSC- or DiR-mCelyvir-injected mice at $48 \mathrm{~h}$ postinjection (upper panel). Bioluminescence images are shown in the lower panel. Numbers in the tumors/organs coincide with those indicated in the graph, which shows the average radiant efficiency of the fluorescence in the tissues of the test groups and control group. (E) Tumor samples were analyzed using a confocal microscope, arrows point out $\mathrm{DiR}^{+}$cells.

Interestingly, the tumors inoculated in left flanks, (noninjected i.t. with ICOVIR5), also showed a size reduction in the three treatment groups when compared to the control group; with a slightly higher tumor growth inhibition in mCelyvir-treated groups (Figure 4D). However, tumors were still growing over time until the end of experiments.

In order to confirm the ICOVIR5 replication in injected tumors, we analyzed the copy of Ad genomes by qPCR. Only tumors of groups treated with the injected ICOVIR5 showed a moderate amplification of Ad E4 gene and there were no differences between ICOVIR5 and mCelyvirICOVIR5 treated mice (Figure 4E). Ad genomes were not detected in left flank tumors (data not shown), indicating that the volume reduction was not a direct effect of virusmediated oncolysis.

We could observe that the treatment of tumorbearing animals only with i.p.-injected mCelyvir inhibited tumor growth despite the lack of ICOVIR5 replication in mMSC. Because it is well known that MSCs per se could positively or negatively modify the tumor progression, we compared the effect of mCelyvir and non-infected mMSCs in this CMT64-6 tumor model. Our results showed that mMSCs had no effect over tumor growth, while mCelyvir again induced a significant reduction in tumor size (Supplementary Figure 4), indicating that their antitumor effect was due to the combination of Ad-infected mMSCs and $\mathrm{Ad}$, and not to mMSCs alone.

Overall these findings demonstrate that both ICOVIR5 and ICOVIR5-infected mMSCs provide therapeutic benefit in the treatment of CMT64-6 tumors, and that the combination of both exhibits a higher therapeutic effect, suggesting that mMSCs carrying ICOVIR5 convey more treatment benefit than just serving as a viral carrier alone.

\section{In vitro mCelyvir do not affect CMT64-6 viability, but produce pro-inflammatory cytokines}

To further investigate the therapeutic effect of mCelyvir in CMT64-6 tumor treatment, we studied a possible direct toxicity of mCelyvir to CMT64-6 cell line by performing coculture experiments. First, we performed transwell assays using microporous inserts of $0.4 \mu \mathrm{m}$ pore size that allow the passage of small molecules but not cells. mMSCs or mCelyvir were plated in the upper compartment, while CMT64-6 cells were plated in the lower compartment, to assay the effect of molecules secreted by $\mathrm{mMSCs} / \mathrm{mCelyvir}$ in CMT64-6 cell viability. After 3 days, we evaluated the number of CMT64-6 cells using a MTT assay. No differences were observed in cocultures compared to CMT646 cultures (Figure 5A).

In order to determine whether cell-cell contact is necessary for a possible toxic effect, mCelyvir or mMSC were cocultured with CMT64-6 for 3 days. Annexin V staining was analyzed by flow cytometry. No significant differences were observed in the percentage of apoptotic CMT64-6 cells (CD90- Annexin V+) when cocultured with mMSCs or mCelyvir. By contrast CMT64-6 died by apoptosis when infected with ICOVIR5 (Figure 5B). These experiments indicate that the in vitro coculture of CMT64-6 with mCelyvir does not affect the growth or viability of the tumor cells. We next examined if the therapeutic effect of mCelyvir could be due to anti-angiogenesis effects. To analyze the possible anti-angiogenic role of mCelyvir, we analyzed the expression profile of angiogenesisrelated proteins by mMSCs in their basal state and after ICOVIR5 infection (mCelyvir) (Supplementary Figure 5A and $5 \mathrm{C}$ ). Most noticeable was the expression pattern of the antiangiogenic chemokine CXCL10 (IP-10), which was not expressed by intact mMSCs but it was produced by ICOVIR5-infected mMSCs (Figure 5C). Moreover, we studied tumor angiogenesis by immunohistochemistry. Staining of endothelial cells with Isolectin B4 (BSI-B4) revealed no changes in the number or morphological distribution of vessels in the tumors (Figure 5D).

The upregulation of CXCL10 secretion after Ad infection of mMSCs was confirmed using an ELISA assay, which revealed levels of $800 \mathrm{pg}$ of CXCL10 per mL of supernatant, $24 \mathrm{~h}$ after infection (Figure 6A). Previous studies have shown that Ad infection induces the expression of CXCL10 in mouse kidney epithelium-derived cells in a 
A

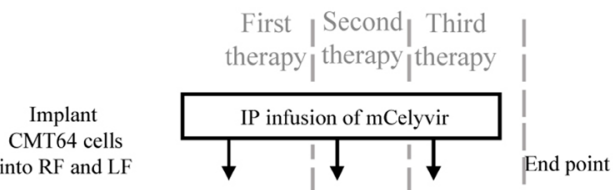

into RF and $\mathrm{L}$

Day-11
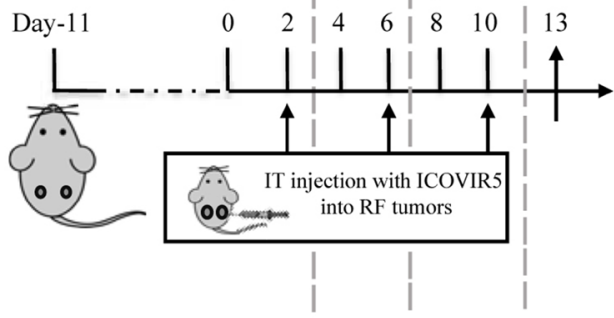

B

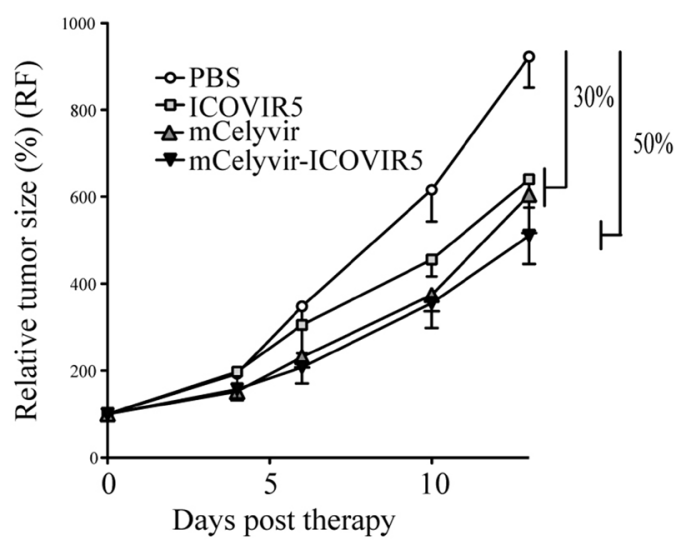

C

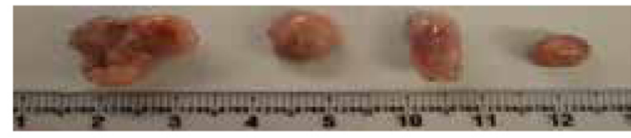

PBS ICOVIR5 mCelyvir $\begin{gathered}\text { mCelyvir- } \\ \text { ICOVIR5 }\end{gathered}$

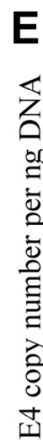

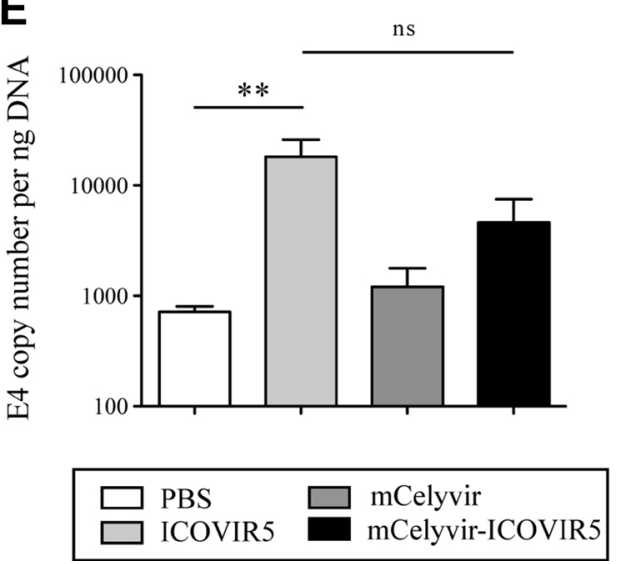

\begin{tabular}{|l|c|c|}
\hline Groups & IP & IT \\
\hline PBS & PBS & PBS \\
\hline ICOVIR5 & PBS & ICOVIR5 \\
\hline mCelyvir & mCelyvir & PBS \\
\hline mCelyvir-ICOVIR5 & mCelyvir & ICOVIR5 \\
\hline
\end{tabular}

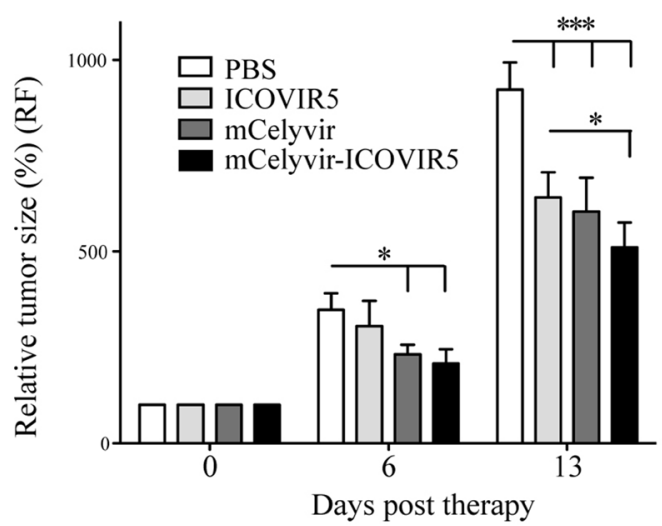

D

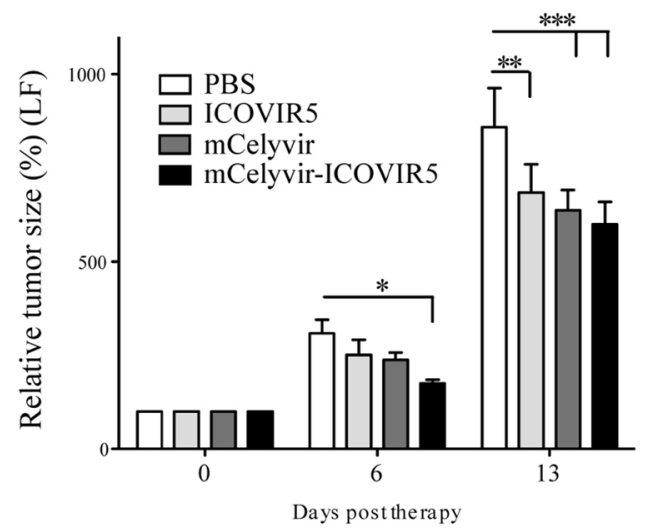

Figure 4: Anti-tumor activity of mCelyvir in the syngeneic mouse model of CMT64-6 tumors. (A) In vivo experiment scheme: CMT64-6 cells were inoculated subcutaneously in C57BL/6 mice. Animals were treated i.p. with mCelyvir/PBS, and $48 \mathrm{~h}$ later with ICOVIR5/PBS (i.t.). Subsequently, the animals were investigated for antitumoral responses by measuring the tumoral volume. (B) For in vivo tumor volume experiments, tumors were measured periodically with a caliper, and volume was calculated. Both graphs show relative size of right flank tumors. (C) Representative photographs of tumors reflecting size at the end point (13 days). (D) Graph shows relative size of left flank tumors, as a readout of therapeutic distant effect. (E) Right flank tumors were harvested from each animal and the amount of viral DNA was measured by quantitative PCR (E4 copies). ANOVA was performed and statistical significance was defined as $* P<0.05, * * P<0.01$ and $* * * P<0.001$. 
NF-kB-dependent manner. The mechanism underlying the upregulation of CXCL10 is dependent on Akt signaling [28]. To analyze whether NF-kB is activated in mMSCs after ICOVIR5 infection, we transduced these cells with a NF-kB promoter driven luciferase reporter system for detecting NF-kB activation [29]. When infected with ICOVIR5 (mCelyvir), cells exhibited a dramatic increase in luciferase activity, indicating NF-kB-driven luciferase expression (Figure 6B). We also confirmed the activation of Akt by Western Blot, using phospho-specific Akt antibody. In addition, we found an increase in the activation of phospho-Jun after ICOVIR5 infection (Figure 6B).

$\mathrm{NF}-\kappa \mathrm{B}$ is a transcription factor that plays a key role in modulating the immune response to infection, regulating innate and adaptive immune response genes. To determine whether infection of mMSCs with ICOVIR5 could trigger an immune system response, we compared the expression profile of a panel of factors involved in immune activation from mMSCs or mCelyvir (Figure 6C and Supplementary Figure 5B). Again, an increase of CXCL10 expression after Ad infection was observed. Furthermore, a higher expression of other proteins with inflammatory and chemoattractant activity, such as CCL5 (RANTES), CXCL1, M-CSF, and IL-6 (Figure 6C) was also detected. Interestingly, most of those cytokines have been previously shown to be regulated by NF-kB [30].

\section{mCelyvir induce immune infiltration in CMT64- 6 tumors}

Our previous results show a notable increase in CXCL10 secretion, among other proinflammatory cytokines, in mMSCs when infected with ICOVIR5. CXCL10 is a chemoattractant for activated $\mathrm{T}$ cells. In vitro CXCL10 induces the migration of mouse lymphocytes (Supplementary Figure 6A) and in vivo preferentially attracts activated lymphocytes to the areas of inflammation and tumors [31]. To further investigate a proinflammatory role of mCelyvir in vivo, we evaluated whether the mCelyvir treatment of CMT64-6 tumors would lead to an increase lymphocyte infiltration in treated tumors. Flow cytometry analysis of tumors revealed that percentages of tumor-infiltrating $\mathrm{CD}^{+}$and $\mathrm{CD}^{+} \mathrm{T}$ cells were higher in right flank tumors of mice treated with the combined treatment (mCelyvir-ICOVIR5) (Figure 7A and Supplementary Figure 7A). In the groups of tumors treated with ICOVIR5 (i.t.) a significant increase of $\mathrm{CD}^{+} \mathrm{T}$ cells was detected in the right flank tumors (Figure 7A). These results were corroborated by $\mathrm{CD}^{+} \mathrm{T}$ cell-immunohistochemistry analysis (Figure 7B). Interestingly, we also found a higher presence of CD45 cells in the groups of mice treated with ICOVIR5 and / or mCelyvir (Supplementary Figure 6B). Moreover, in the non-treated left flank tumors a significant increase in $\mathrm{CD}^{+} \mathrm{T}$ cells infiltration was detected only in mCelyvirICOVIR5 group (Figure 7A).
We also analyzed the lymphocyte subpopulations in peripheral blood and spleen. In mice treated with mCelyvir-ICOVIR5 an increase of $\mathrm{CD}^{+}$and $\mathrm{CD}^{+}$ lymphocytes were detected in peripheral blood and only of $\mathrm{CD}^{+}$in spleen (Figure 7C). In mice treated only with ICOVIR5, a moderate increase in $\mathrm{CD}^{+}$cells was also detected in peripheral blood and spleen, but no changes were found in $\mathrm{CD}^{+}$lymphocytes (Figure 7C).

Since $\mathrm{CD}^{+}$cells were the higher infiltrating lymphocyte population, especially in the group of mice treated with mCelyvir-ICOVIR5, we decided to study the ex vivo IFN $\gamma$ production upon different stimulations in spleen-derived $\mathrm{CD}^{+} \mathrm{T}$ cells obtained from treated mice. To test the induction of anti-Ad immunity, IFN $\gamma$ secretion was analyzed upon stimulation with a peptide from E1b (VNIRNCCYI) (Supplementary Figure 7B and 7D). Only animals of groups treated with ICOVIR5 (i.t.) showed T lymphocyte activation against E1b (Figure 7D). However, there was no difference in anti-Ad $\mathrm{CD}^{+}$cell activation in the group treated only with ICOVIR5 compared to the group treated with the combined therapy mCelyvirICOVIR5. Interestingly, the proportion of splenocytes $\mathrm{CD}{ }^{+} \mathrm{IFN} \gamma^{+}$activated against CMT64-6 tended to increase in both mCelyvir-treated groups (Figure 7D).

Altogether these results demonstrate a correlation between the lymphocyte increase in tumors, spleen and blood and the therapeutic effect of ICOVIR5 when administered alone or with mCelyvir, suggesting that the administration of both therapeutic agents triggers a higher antitumor immune response.

\section{DISCUSSION}

Clinical trials with oncolytic Ad point to a limited efficacy due to insufficient viral delivery to tumor and to host-antiviral immune responses [3]. The use of MSCs as vehicles for oncolytic Ad has been shown to increase its efficacy [8]. Several groups, including ours, have explored the possibility of using those cells in animal models as vehicles to avoid aforementioned limitations. Currently two trials are ongoing using MSCs as cell carriers for oncolytic virotherapies, one using an oncolytic measles virus (NCT02068794), and our clinical study where we use ICOVIR5 (NCT01844661). We previously performed an exploratory study in children with refractory metastatic neuroblastoma based on the intravenous infusion of human Celyvir. The tolerance to the treatment was excellent and clinical responses were documented including complete remissions $[12,16]$.

Based on our experience using MSCs as antitumor agents, we hypothesized that MSCs behave more than just simple cell carriers, e.g. inducing antitumor immune activation. Adenoviral infection induces the expression and release, in vivo and in vitro, of proinflammatory cytokines, including IL-6, IL-8, tumor necrosis factor alpha (TNF- $\alpha$ ), macrophage inflammatory protein-1 alpha (MIP-1 $\alpha$ ), 
A

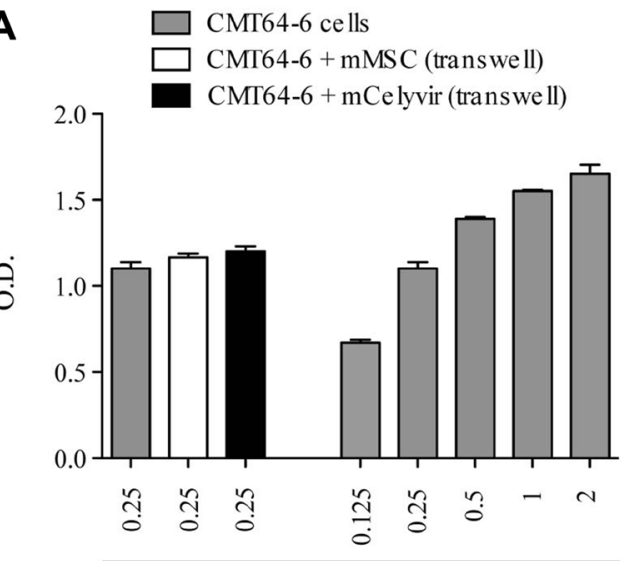

Number of CMT64-6 cells (x 10e $\left.{ }^{5}\right)$
B

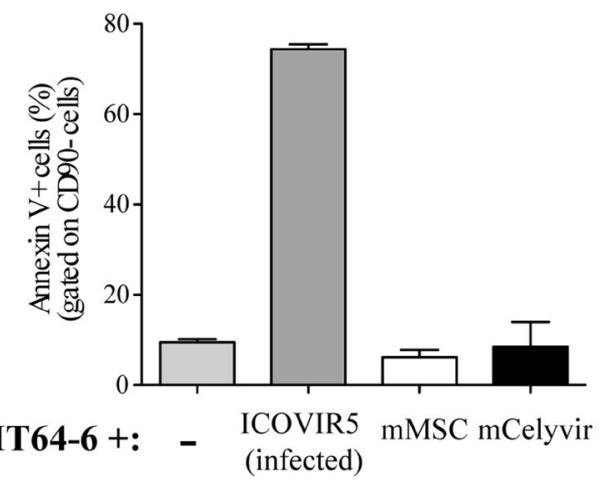

C
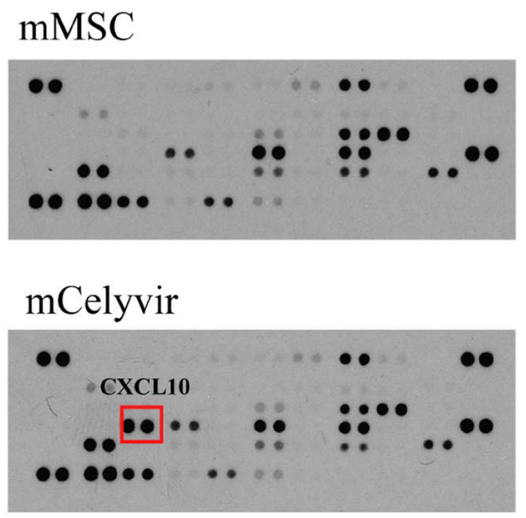

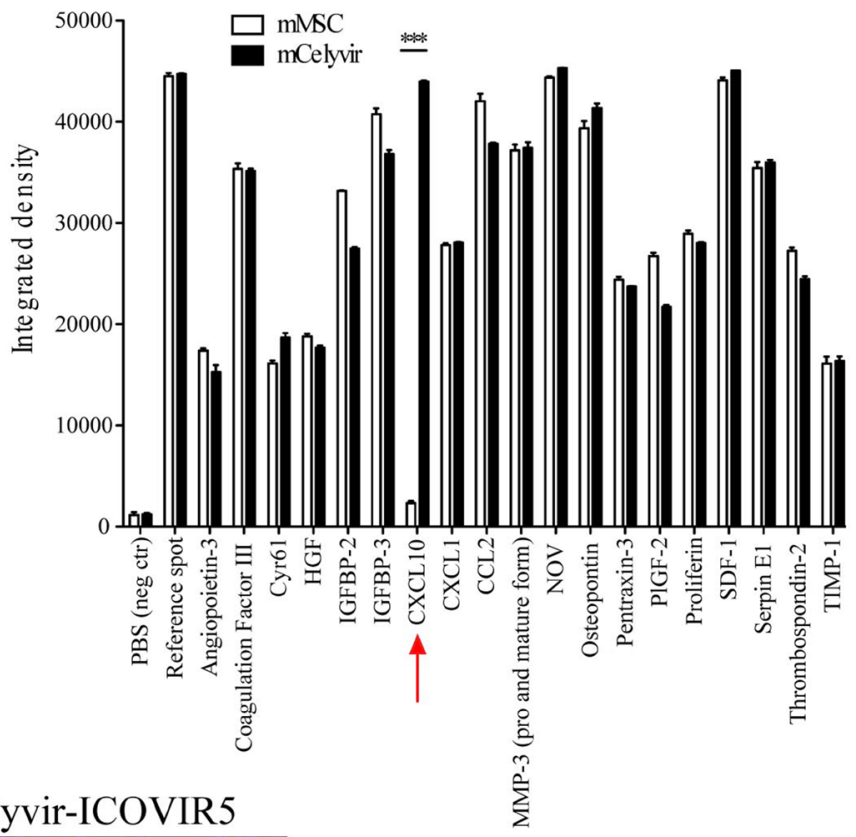

mCelyvir-ICOVIR5

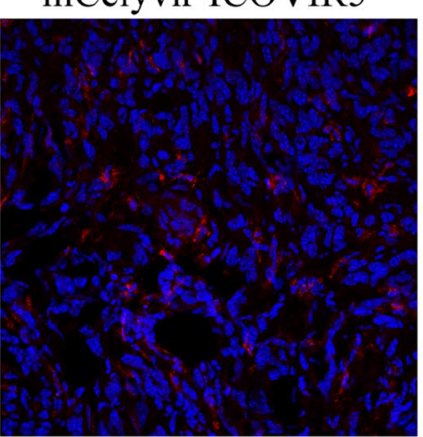

BS-I Isolectin B4

DAPI

Figure 5: Study of mechanisms of action of Celyvir on CMT64-6. (A) CMT64-6 cells were cultured in the presence of factors produced by $\mathrm{mMSC} / \mathrm{mCelyvir}$ in transwell with of $0.4 \mu \mathrm{m}$ pore size. CMT64- 6 cell number was measured by MTT after 3 days. A serial dilution curve of CMT64-6 cells was used as a standard curve. (B) CMT64-6 cells and mMSCs/mCelyvir were cocultured during 3 days and the cell death was measured by the proportion of apoptotic cells (Annexin $\mathrm{V}^{+}$cells) within the CD90- subset by flow cytometry. ICOVIR5 Infected CMT64 cells were also analyzed (as a positive control). (C) Supernatants from mMSC/mCelyvir after $24 \mathrm{~h}$ of culture were analyzed for the presence of angiogenesis-related proteins. The arrays show the pattern of each condition. The graph shows pixel intensity quantification of the dots corresponding to each molecule measured. (D) Sections from tumors of mice being treated with PBS or with mCelyvir-ICOVIR5 were stained for BS-I Isolectin B4 by immunofluorescence for blood vessel density evaluation (red). Student's $t$ test was performed and statistical significance was defined as $* * * P<0.001$. 
CCL5 (RANTES) and interferon-gamma (IFN $\gamma$ ) [32]. Using murine MSCs and a human Ad, as ICOVIR5, we did not observe any expression of TNF- $\alpha$, MIP- $1 \alpha$ and IFN $\gamma$; but we found overexpression of CXCL10, CCL5, IL-6 and M-CSF. Transcriptional regulation of CXCL10 following infection with Ad vectors, differs significantly from the transcriptional mechanisms activated in response to TNF- $\alpha$ and IFN $\gamma$ [33]. In addition, in kidney-derived epithelial cells, RGD-modified Ad (as ICOVIR5) rapidly activate Akt that contribute to the Ad induction of CXCL10 through its effects on NF-kB pathway [28]. Ad activation of MAPK and ERK signal transduction pathways, in a post-internalization step of viral entry, contributes to CXCL10 expression. Some of these mechanisms could be occurring in mMSCs after Ad infection, inducing the CXCL10 and CCL5. Strikingly, the production of these chemokines by MSCs have been strongly related with the polarization of these cells to proinflammatory and antitumoral phenotype $[34,35]$.

mCelyvir home to the tumor during the first 24 hours. However, the production of inflammatory proteins after Ad infection of mMSCs is unlikely to induce a high number of tumor infiltrating lymphocytes (TILs). Our data of immune cells infiltrating the tumors indicate that mCelyvir alone is not sufficient to increase the number of TILs, but when we combined mCelyvir with ICOVIR5 (i.t.) a higher increase of TILs was detected than in mice treated only with ICOVIR5. These data suggest that some level of intra-tumor Ad-replication could be necessary for an effective TILs presence, a hypothesis supported by other immunocompetent mouse models [36]. Moreover, in our model, the higher number of TILs correlates with
A

CXCL10
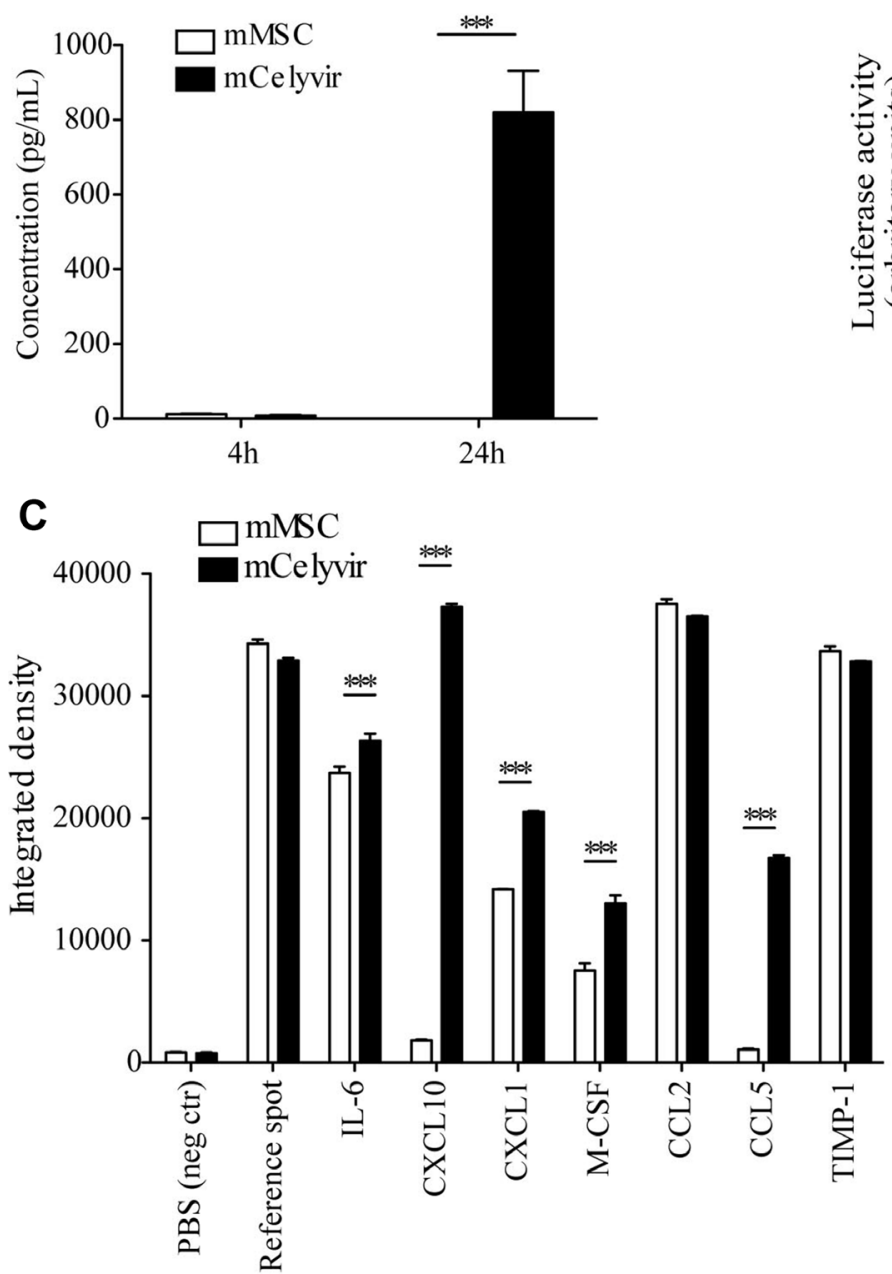

B
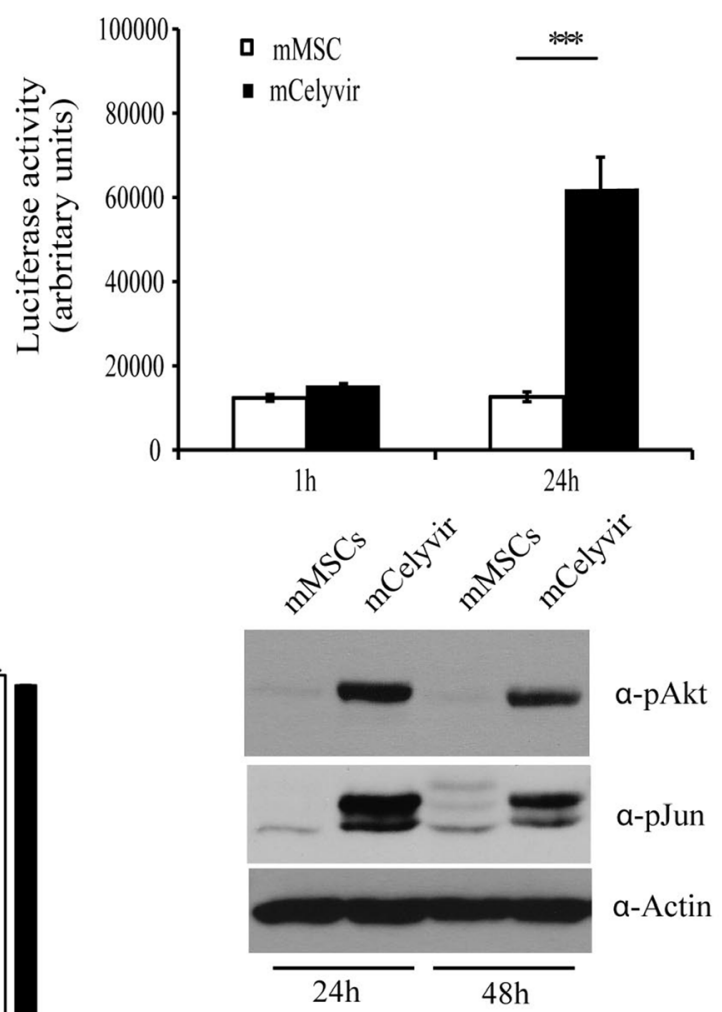

Figure 6: Cytokines secreted by mMSC vs mCelyvir. (A) Quantification of CXCL10 production on mMSC/mCelyvir after $24 \mathrm{~h}$ by ELISA CXCL10. (B) Up panel, mMSC were transduced with a lentiviral system for detecting differences in activation of NF-kB levels by luciferase expression after ICOVIR infection $(1 \mathrm{~h} / 24 \mathrm{~h})$. The graph shows luciferase activity. Down panel, Western Blott performed with phosphoAkt and phospho-Jun specific antibodies on mMSC and mCelyvir after $24 \mathrm{~h}$ or $48 \mathrm{~h}$ of Ad infection. Anti-actin antibody was used as a loading control. (C) Pixel intensity quantification of the array blot (original shown on Supplementary Figure 5) for the evaluation of the production of different key factors of the immune response. Student's $t$ test was performed and statistical significance was defined as $* * * \mathrm{P}<0.001$. 
A Gated on CD3+ T cells
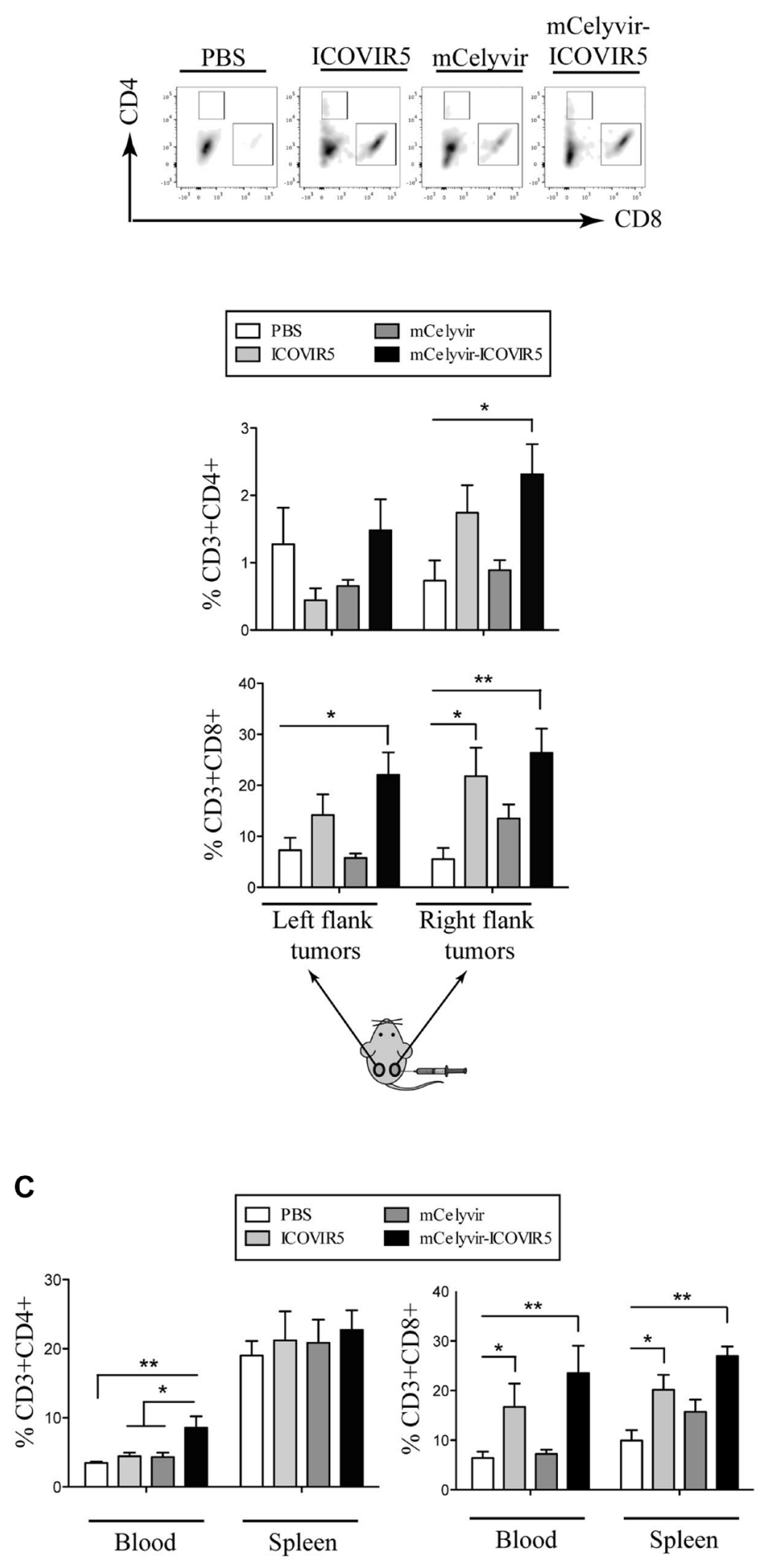

B

\section{CD8 DAPI}
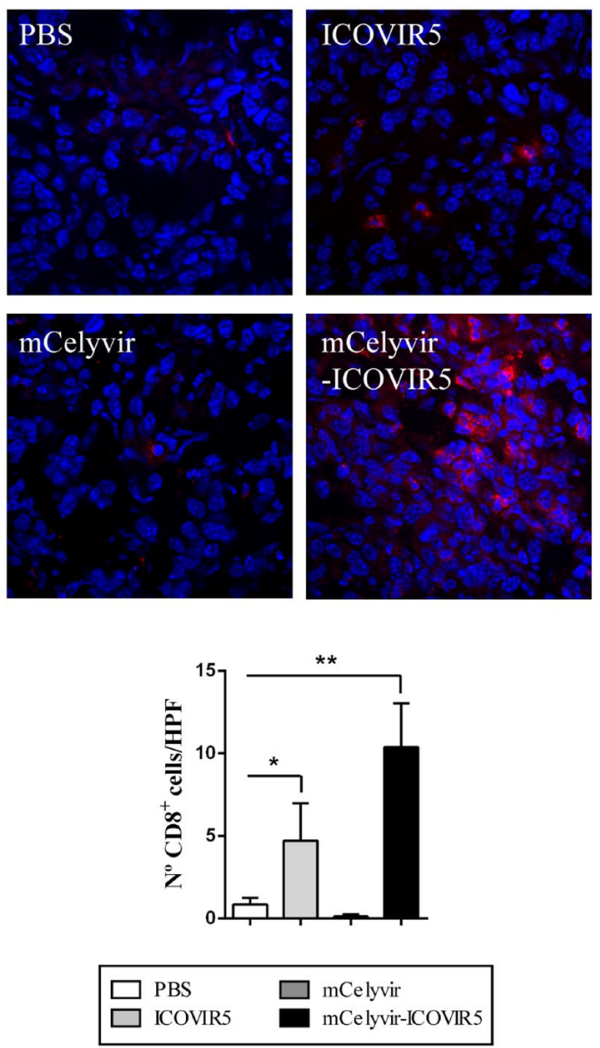

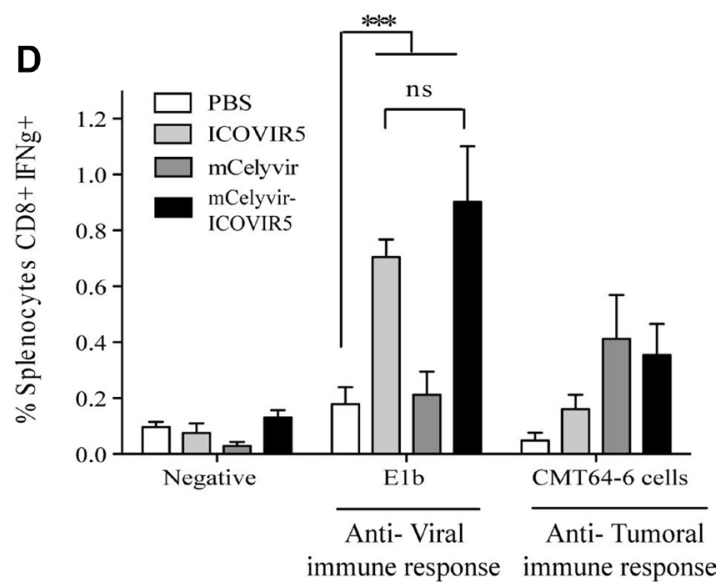

Figure 7: mCelyvir-ICOVIR5 treatment increases tumor lymphocyte infiltration. (A) Right and left flank tumors of mice treated as explained in Figure 4 were disaggregated and percentages of $\mathrm{CD}^{+}$and $\mathrm{CD}^{+} \mathrm{T}$ cells (within $\mathrm{CD} 3^{+}$cell subset) were analyzed by FACS. (B) Immunohistochemistry of tumors confirmed higher number of CD8 ${ }^{+}$lymphocytes infiltration (red) in ICOVIR5- and mCelyvirICOVIR5- treated groups. DAPI counterstaining (blue). (C) Percentages of CD8 ${ }^{+}$and $\mathrm{CD} 4^{+} \mathrm{T}$ cells (within $\mathrm{CD} 3^{+}$cell subset) were analyzed by FACS on blood and spleen of mice of each group. (D) Proportion of $\mathrm{CD} 8^{+}$IFN $\gamma^{+}$splenocytes upon different stimulations (a major adenoviral peptide E1b or a lysate of CMT64) was determined by FACS in the splenic CD8 ${ }^{+}$cells of mice of each group. This experiment was performed three times and a representative one is shown. Results were analyzed using one way ANOVA followed by Tukey's post hoc test. Statistical significance was defined as $* P<0.05, * * P<0.01$ and $* * * P<0.001$. 
a better antitumor effect in the group of mice treated with combined therapy mCelyvir-ICOVIR5, suggesting a main role of antitumor immune activation for the efficacy of this therapeutic strategy.

A major limitation in the advancement of this field is the lack of adequate immune- and Ad replication permissive-competent models. Our group previously studied a cotton rat animal model, that is a semi-permissive host for Ad replication [10]. We used rat MSCs (rMSCs) loaded with human oncolytic Ad to evaluate the antiadenoviral immune response in mice treated with oncolytic Ad or with oncolytic Ad-infected rMSCs. Ad-loaded rMSCs reduced in vivo the amount of anti-Ad antibodies and ex vivo the splenocyte IFN $\gamma$ production. We also studied the effect of Ad-loaded rMSCs in subcutaneous tumors generated in the flank of the cotton rats by injecting LCRT fibrosarcoma cells. We observed that tumors injected with Ad-loaded rMSCs, exhibited higher amount of viral DNA than tumors injected only with naked Ad [10]. However, in that study, we couldn't find a correlation between antitumor efficacy and treatment with oncolytic Ad or Ad-loaded rMSCs. In the present study there were no differences in the amount of Ad genomes or anti-Ad $\mathrm{CD}^{+}$IFN $\gamma^{+}$splenocytes between ICOVIR5 and mCelyvirICOVIR5 groups. In this sense, it should be noted that rMSCs, but not mMSCs, are permissive to human Ad infection and replication [10, 37]. Moreover, Ad-loaded rMSCs maintained their immunosuppressive properties. In contrast, human Ad infection of mMSCs induced apoptosis. Interestingly, when we tested $\mathrm{T}$ lymphocyte activation against CMT64-6 extracts, a slight increase was detected in both mCelyvir-treated groups. We assessed the tumor-specific immune responses using CMT64-6 cells transduced with GFP-expressing lentiviral vectors, and then tested $\mathrm{T}$ lymphocyte activation against GFP peptides as a model of tumor-like antigen; however, we did not detect $\mathrm{T}$ cell activation (data not shown). Although we have not demonstrated an increase in the antitumoral activation of T cells in mice treated with mCelyvir, we cannot exclude that this is actually happening in our model.

The higher antitumor effect of the combined mCelyvir-ICOVIR5 therapy in our model is very interesting because mMSCs do not produce new adenoviral particles after Ad infection (in fact they undergo apoptosis), but are still triggering an antitumor response. A potential mechanism of action would be that adenoviral particles are transmitted to tumor cells without an extracellular transmission. Hamada et al. (2007) demonstrated that A549 cells bearing replicationcompetent Ad delivered Ad through cell fragments, originated by apoptotic blebbing, to cancer cells [38]. They observed engulfment of cell fragments only in proliferative malignant cells and not in non-proliferative normal cells. In addition, their carrier cell-mediated adenoviral infection produced cytotoxic $\mathrm{T}$ lymphocyte responses to tumoral cells as well as Ad [38]. Here, we did not observe a clear
$\mathrm{CD}^{+}$cell infiltration in tumors of mice treated only with mCelyvir, but we observed a minor increase of $\mathrm{CD} 8^{+} \mathrm{IFN} \gamma^{+}$ in splenocytes of this group.

In summary, our results not only demonstrate the capacity of mCelyvir to migrate toward tumors but also document a new role for MSCs when used as cell carriers of oncolytic Ad based on their ability to produce proinflammatory cytokines. These data show how the use of MSCs as carriers of oncolytic Ad can be beneficial for two reasons: first, it is a way to directly transport the Ad to the tumors and second, the infected MSCs can increase the antitumor response working collaboratively with the action of the oncolytic Ad. These findings have implications for patients with metastatic cancer treated with oncolytic virotherapy.

\section{MATERIALS AND METHODS}

\section{Cell culture}

Cells were cultured in Dulbecco's Modified Eagle's Media supplemented with 10\% fetal bovine serum (FBS) as well as streptomycin $(100 \mathrm{mg} / \mathrm{mL})$ and penicillin $(100 \mathrm{U} / \mathrm{mL})$ at $37^{\circ} \mathrm{C}$ in a humidified atmosphere with $5 \%$ $\mathrm{CO}_{2}$. The murine non-small-cell lung carcinoma cell line CMT64 was kindly gifted by Dr. Sthepan Kubicka from Hannover Medical School (Hannover, Germany). The clone CMT64-6 was isolated from the cell line CMT64. The clones were obtained by diluting 5 cells in $1 \mathrm{ml}$ and seeding $200 \mathrm{ml}$ per well. We amplified the cells and we infected monolayers $\left(4 \times 10^{5}\right)$ of the different clones with ICOVIR15 with 200 MOI. Five days post-infection we obtained a cellular extract and quantified the virus by hexon protein staining [39]. We also infected parental cell line and clone 6 with different MOIs of AdTL and evaluated transduction on a fluorescence microscopy. CMT64-6 cells were transduced with a replicationdeficient lentiviral vector containing firefly-luciferase and GFP expression cassettes (provided by Dr A. Rodríguez, Department of Molecular Biology, Universidad Autónoma de Madrid, Spain) for in vivo homing experiments (referred to as CMT64-6Luc/GFP). HEK293, B16 and RENCA cells were obtained from the American Type Culture Collection (ATCC, Manassas, VA). Human MSCs were obtained from Lonza (Basel, Switzerland). mMSCs were obtained as previously described [26]. Briefly, abdominal adipose tissue from C57BL/6 mice was digested with collagenase IV (Sigma-Aldrich, Madrid, Spain), filtered through a sterile $70 \mu \mathrm{M}$ nylon mesh cell strainer (Fisher Scientific, Waltham, MA) and cultured in MesenCult medium (Stem Cell Technologies, Vancouver, Canada). Non-adherent cells were discarded through subsequent culture passages. The mMSCs characterization was verified by: (I) fibroblast morphology of adherent cells; (II) flow cytometry expression profile analysis using monoclonal antibodies to mouse CD44 (clone IM7), CD90 (clone 52-3.1), 
Sca1 (clone D7), CD11b (clone M1/70), CD45 (clone 30-F11) (eBioscience, Barcelona, Spain), and CD11b (BD Bioscience, Madrid, Spain); and (III) verification of multilineage differentiation potential in adipogenic, osteogenic and chondrogenic phenotype by culture mMSCs in specific cell culture media (Lonza, Barcelona, Spain) followed by lipidic drop (oil red O), bone ECM (alizarin red) and chondrogenic glycosaminoglycans in the presence of TGF- $\beta$ (alcian blue) staining respectively (Supplementary Figure 1). mCelyvir were mMCs infected with ICOVIR5 at an MOI of 200 p.f.u. per cell.

\section{Oncolytic adenoviruses}

ICOVIR5 has been extensively described elsewhere $[22,23,40]$. Briefly, ICOVIR5 (Ad-DM-E2F-KDelta24RGD) is an optimized oncolytic Ad that combines E1a transcriptional control by an insulated form of the E2F promoter with the Delta24 mutation of E1a to improve the therapeutic index of AdDelta24RGD. ICOVIR5 also contains the Kozak sequence at the Ela start codon, which is important to restore E1a expression and viral replication to AdwtRGD levels in tumor cells. AdTL vector, containing recombinant fiber-RGD protein and expressing the firefly luciferase and EGFP, was described previously [24, 25]. It was used to measure transduction efficiency by FACS or fluorescence microscopy. ICOVIR15Luc was constructed by Dr. Luis Rojas (Catalan Institute of OncologyIDIBELL) and it will be described elsewhere. This virus contains a splicing acceptor signal connected to the firefly luciferase gene inserted after the fiber gene of ICOVIR15 [41]. To quantify the viral replication, cells were infected with different MOIs of ICOVIR5. Cells were collected $72 \mathrm{hr}$ after infection and the total DNA was isolated using a DNeasy tissue kit (Qiagen, Valencia, CA) and quantified using a spectrophotometer (NanoDrop; Thermo Scientific, Pittsburgh, PA). Adenoviral E4A gene expression was quantified via quantitative PCR (qPCR) with iQ SYBR Green supermix (Bio-Rad, Hercules, CA), using primers and protocol described elsewhere [42, 43]. Each sample was analyzed in triplicates. Results are presented as E4A copy number/ng of DNA. In ICOVIR15Luc-infected cells, luciferase activity was measured in the lysates of infected cells using Luciferase Assay System (Promega, Madrid, Spain). Luciferase expression was also analyzed in the lysates by western blotting, that was conducted using standard protocols as described previously [44]. Primary antibodies employed were monoclonal antiluciferase antibody and mouse monoclonal anti-tubulin antibody (clone LUC-1 and clone DM1A respectively, Sigma-Aldrich). To quantify infectious viral progeny of CMT64-6 cells, mMSCs, hMSC, HEK-293 (as permissive positive control) and B16 (as non-permissive negative control) supernatants of infected cells were collected $96 \mathrm{~h}$ after infection and incubated with HEK293 cells in serial ten-fold dilutions, as per the Adeno-X Rapid Titer Kit protocol (Clontech, Mountain View, CA). After 48 h, the cells were fixed/permeabilized with methanol and stained for hexon plaques and viral titer was determined according to the manufacturer's protocol. The titration units (infection unit $/ \mathrm{mL}$ ) values quantified through this protocol are similar to plaque forming units (pfu). To analyze the toxicity effect of ICOVIR5 on mMSCs, cell viability was evaluated by trypan blue exclusion method at $24 \mathrm{~h}, 48 \mathrm{~h}$ and $72 \mathrm{~h}$ post-infection (200 MOI). There was a total of 3 wells per condition. The experiment was repeated 3 times. Apoptosis at $48 \mathrm{~h}$ post-infection time point was measured using Annexin V detection kit (BD Bioscience) and then analyzed by flow cytometry (FACSCalibur; BectonDickinson, Mountain View, CA, USA).

\section{mMSCs-CMT64-6 cell coculture and cytotoxicity assay}

To evaluate in vitro the toxicity of mCelyvir to CMT64-6 cell line, mMSCs were infected with ICOVIR5, and, after $2 \mathrm{~h}$, Ad was removed by washing out twice with PBS. CMT64-6 cells were added to the wells and cocultured during 3 days (or 5 days, data not shown). Cells were then stained with CD90 (clone 5E10, eBioscience), and Annexin $\mathrm{V}$ and apoptosis in CD90-negative cells (CMT64-6 cells) were analyzed by flow cytometry (FACSCalibur). For transwell cultures (Figure 5A), $2.5 \times 10^{5}$ mMSCS or mCelyvir were plated in the upper compartment (transwell $0.4 \mu \mathrm{m}$ pore size; Corning, NY), while the same number of CMT64-6 cells were plated in the lower compartment. A standard curve with different number of CM64-6 cells plated in the lower compartment, but without mMSCs/ mCelyvir in the upper compartment, was also done. After 3 days, upper compartment was removed and cell viability assay was performed in CMT64-6 cells using MTT Kit according to manufacturer's instructions (Roche, Basel, Switzerland). Each value from these indicated assays represents the mean \pm SEM of triplicate measurements from two independent experiments.

\section{Luciferase assay}

We determined the activation of $\mathrm{NF}-\kappa \mathrm{B}$ by using a luciferase reporter system [29]. Replication incompetent lentiviral vectors were created using the pHAGE NF$\kappa B-T A-L U C-U B C-G F P-W$ plasmid, a gift from Darrell Kotton (Addgene plasmid \# 49343). The plasmid encodes the NF- $\kappa \mathrm{B}$ consensus binding sequence upstream of the minimal TA promoter of the herpes simplex virus followed by the firefly luciferase gene, as well as the GFP gene upstream of the ubiquitin-C promoter. Transduction of mMSCs was performed overnight and GFP expression was assessed by flow cytometry. For luciferase-reporter assays, cells were infected with ICOVIR5 and, 24 hours later, $10^{4}$ cells were lysed and luciferase activity was assayed with the luciferase assay system (Promega), according to the manufacturer's instructions. Activation of Akt and c-Jun was analyzed in the lysates of these cells by western 
blotting using the following mouse monoclonal antibodies: anti-phospho-Akt-Ser473 (clone 2118, Epitomics), antiphospho-c-Jun (clone KM-1, Santa Cruz Biotechnology) and anti-Actin (clone AC-15, Sigma-Aldrich).

\section{Animal experiments}

We established subcutaneous tumors of CMT64-6 or CMT64-6Luc cells injecting $5 \times 10^{6}$ cells (or $2.5 \times 10^{6}$ cells for in vivo imaging) into the flanks of 6-8 weeks old C57BL/6 syngeneic mice. Tumors were grown for 10-12 days to a size of 6-7 $\mathrm{mm}$ in diameter. The studies were approved by Spanish "Animal Ethics Committee" in compliance with European Union Directives. Animal studies performed at the University of Chicago were approved by "UC Institutional Animal Care and Use Committee". For the efficacy experiments we injected intraperitoneally mMSCs/ mCelyvir in CMT64-bearing mice $\left(1 \times 10^{6}\right.$ cells/mouse $)$. For in vivo optical imaging of $\mathrm{mMSCs} / \mathrm{mCelyvir}$ homing to CMT64-6Luc tumors, mMSCs/mCelyvir were incubated with $320 \mathrm{mg} / \mathrm{mL}$ DiR buffer for $30 \mathrm{~min}$ at $37^{\circ} \mathrm{C}$ according to the protocol of XenoLight DiR (Caliper Lifesciences, Hopkinton, MA). Then DiR-labeled mMSCs/mCelyvir were washed twice with PBS buffer and intraperitoneally injected in CMT64-6Luc tumor-bearing mice $\left(2 \times 10^{6}\right.$ cells/ mouse). Some cells were analyzed by flow cytometry for DiR staining. For visualizing CMT64-6Luc tumors, mice were intravenously injected with $150 \mathrm{mg} / \mathrm{kg}$ body weight of firefly luciferin (Promega, Madison, WI), 3 minutes before imaging and anesthetized with isofluorane during the procedure. The homing of $\mathrm{mMSCs} / \mathrm{mCelyvir}$ to tumors was monitored using IVIS system at 4, 24 and 48 hours postinjection of $\mathrm{mMSCs} / \mathrm{mCelyvir}$ to obtain serial fluorescence images. Both, the fluorescent and bioluminescent imaging analysis were conducted with the IVIS 200 in vivo imaging system (Caliper). Bioluminescence images of tumors were taken with the exposure time of 30 seconds. For ex vivo imaging, tumors, spleen and lymph nodes were collected at $48 \mathrm{~h}$ post $\mathrm{mMSC}$ injection. Bioluminescent and fluorescent images of each mouse and sample were analyzed using Living Image software (Xenogen, Alameda, CA). Regions of interest (ROI) were drawn over the signals, and average radiant efficiency was quantified in $\mathrm{p} / \mathrm{s} / \mathrm{cm}^{2} / \mathrm{sr}$. The experiment was performed 3 times $(n=5$ mice per group each time). For in vivo tumor volume experiments, tumors were measured periodically with a caliper, and volume was calculated as $\left(\right.$ length $\times$ width $\left.^{2}\right) / 2$ [45]. The experiment was repeated 3 times ( $n=5$ mice per group). At different time points mice were sacrificed and tumors and spleens were harvested and processed for flow cytometry, histology and E4A copy gene analysis.

\section{Immunofluorescence}

Tumor samples were fixed in $10 \%$ buffered formalin solution and embedded in optimal cutting temperature (OCT) (Tissue-Tek) medium. Cryosections (8-10 mm) were stained for immunofluorescence. Immunofluorescent stains were applied using BS-I Isolectin B4 Biotin Conjugate (Sigma-Aldrich), monoclonal mouse CD8 (clone 53-6.7, eBioscience) and CD45 (clone 30-F11, Biolegend). Briefly, tumor sections were dried at room temperature (RT), washed three times with cold PBS and blocked with $10 \%$ BSA for 30 minutes. Samples were incubated for 2 hours at RT with primary antibodies, washed and incubated for 1 hour at RT with the secondary antibody. Antibodies were used between 5-10 $\mu \mathrm{g} / \mathrm{ml}$. After washing with cold PBS three times, tissues were covered with Prolong Gold anti-fade reagent with DAPI (Invitrogen). Images of antibody-stained sections were acquired using the Sp5 Tandem Scanner confocal microscope running LAS AF software (Leica Microsystems, Barcelona, Spain).

\section{Flow cytometry analysis of immune cell populations}

Single cell suspensions were made from collagenase IV-digested tumors or spleen by mashing cells through a sterile $70 \mu \mathrm{M}$ nylon mesh cell strainer using the rubber end of a $3 \mathrm{~mL}$ syringe into ice-cold PBS. Red blood cells were removed by treatment with ACK Lysis Buffer (Lonza) for four minutes on ice. Peripheral blood was collected on EDTA-coated tubes and treated with RBC buffer (Biolegend, San Diego, CA) to lyse red blood cells. For detection of surface antigens, the cells were stained with primary antibodies for 30 minutes at $4{ }^{\circ} \mathrm{C}$ in fluorescenceactivated cell sorting (FACS) buffer $(0.5 \%$ bovine serum albumin, $0.05 \%$ sodium azide) in PBS. After the cells were washed, secondary antibodies were added in FACS buffer for another 30 minutes at $4^{\circ} \mathrm{C}$. After fluorescent labeling, the samples were washed, acquired with the LSR II flow cytometer (BD Biosciences, Franklin Lakes, NJ) and analyzed using FlowJo analysis software (TreeStar, Cupertino, CA). The primary antibodies used were: monoclonal antibodies to mouse CD45 (clone 30F11), mouse CD3 (clone 145-2C11), CD4 (clone GK1.5), CD8 (clone 53-6.7), CD11b (clone M1/70) and CD11c (clone N418) or an appropriate negative control (isotype immunoglobulins) (eBioscience). All antibodies were used between $5-10 \mu \mathrm{g} / \mathrm{ml}$.

\section{IFN $\gamma$-Intracellular staining}

IFN $\gamma$ production was analyzed by intracellular cytokine staining (ICS) to monitor $\mathrm{CD}^{+}$cells immune responses from splenocytes isolated from treated mice. Spleens were treated as above-mentioned and the splenocyte cell suspension was resuspended in RPMI medium (Gibco). One million of cells were seeded in wells of 96 well plate with U-bottom, where different stimulants were added: (i) PMA (30 ng/mL) and ionomycin (500 ng/mL) (Sigma) as positive controls; (ii) RPMI medium as negative control; (iii) peptide from E1b (VNIRNCCYI); 
(iv) coculture with CMT64-6 cells previously treated during $48 \mathrm{~h}$ with $300 \mathrm{u} / \mathrm{mL}$ of IFN $\gamma$ (Genzyme Cytokine Research Products, Cambridge, MA) [39, 46]. Splenocytes were stimulated overnight, $37^{\circ} \mathrm{C}$. Then, Brefeldin A was added to the wells to a final concentration of $10 \mu \mathrm{g} / \mathrm{mL}$ and incubated for $4 \mathrm{~h}, 37^{\circ} \mathrm{C}$. After the plate was spun and vortexed, the cells were stained for surface antigens, using the antibodies anti-CD3, anti-CD8 previously mentioned. Cells were then incubated in fixation/permeabilization solution during 20 minutes at $4^{\circ} \mathrm{C}$ and washed twice in BD Perm/Wash buffer (using BD Cytofix/Cytoprem, BD Bioscience). The cells were stained for detection of the intracellular marker IFN $\gamma$ using a monoclonal anti mouse IFN $\gamma$ (clone XMG1.2, eBioscience) prepared in Perm/ Wash buffer at $4 \mu \mathrm{g} / \mathrm{ml}$, washed, acquired using the LSR II flow cytometer and analyzed by Flowjo analysis software.

\section{Cytokine array and quantification}

mMSCs and mCelyvir were seeded in p60 Petri dishes. After $24 \mathrm{~h}$, supernatants were collected and the protein pattern was analyzed using proteome profiler array kits. For analyzing the expression profile of angiogenesisrelated proteins, we used the Proteome Profiler Mouse Angiogenesis Array Kit, and for analyzing the cytokine pattern, the Proteome Profiler Mouse Array Panel A kit. Both kits were used according to manufacturer's recommendation (R\&D Systems, Minneapolis, MN).

\section{Enzyme-linked immunosorbent assay (ELISA)}

mMSCs and mCelyvir were seeded at $4 \times 10^{4}$ cells in 24-well plates in $1 \mathrm{~mL}$ medium containing $20 \%$ fetal bovine serum. At the indicated times, culture medium was collected and CXCL10 protein levels were measured by enzyme-linked immunosorbent assay (ELISA) using a commercial kit and following the manufacturer's instructions (Mouse CRG-2/IP-10 Ray Bio ELISA Kit, RayBiotech, Norcross, GA).

\section{In vitro cell migration assays}

Transwells ( $8 \mu \mathrm{m}$ pore filters, BD Biosciences) were coated with $0.1 \%$ gelatin (Sigma) and $5 \times 10^{4} \mathrm{mMSCs} /$ mCelyvir were transferred to the upper chambers. Cells were incubated in the presence of DMEM (negative control) or $2 \times 10^{5}$ of cells (CMT64-6, RENCA or B16 (murine tumoral cell lines), or MEFs (normal fibroblast cells)) in the bottom chamber for 6 or 24 hours. A negative control assay was also performed by incubating the cells with DMEM alone in the bottom chamber. A positive control assay was also included, by incubating cells with DMEM supplemented with 5\% FBS. Migrated cells were fixed and stained with crystal violet. For statistical analysis, cells were manually counted in 10 high-power fields (HPFs). Each experiment was repeated three times $(n=6)$. For splenocyte migration assay, splenocytes were analyzed as previously described [47].

\section{Statistical analysis}

Data were graphed and analyzed using StataSE12 statistical analysis software (college Station, TX) and GraphPad Prism (GraphPad Software, La Jolla, CA). All experiments were performed in a blinded manner and repeated independently under identical conditions. Data distribution was examined first and transformations were applied as appropriate. Results were expressed as the mean \pm SEM and were analyzed as follow: for continuous variables, comparisons between two groups was tested using 2-tailed Student's $t$ test, and comparisons between more than two groups were examined using ANOVA with appropriate post-hoc test. To compare groups, ANOVA was performed, followed by Tukey-Kramer post hoc test if the $P$ value was $<0.05$. Post-hoc analyses were conducted using the Newman-Keuls method for multicomparison procedures. All statistical tests were two tailed. A confidence interval of $95 \%$ and $P$ value $<0.05$ was used to establish significance. Statistical significance was defined as $* P<0.05, * * P<0.01$ and $* * * P<0.001$.

\section{Authors' contributions}

ER participated in the experimental work, data compilation, analysis and writing of the manuscript. TC, DK, AA, MARM, RGH, BA and YH participated in the experimental work and data production. LZ participated in the statistical analysis of the data. RA participated in critical discussion of experimental design and in comments on the manuscript. MSL supervised the work at the University of Chicago and contributed resources and methodological assessment. JGC generated the hypothesis, supervised the work at Instituto de Salud Carlos III (Madrid) site, contributed resources, completed data analysis, and writing the manuscript.

\section{ACKNOWLEDGMENTS}

We are grateful to colleagues who generously provided reagents. We thank Irina Balyasnikova and Jian Qiao (University of Chicago, Chicago, USA) for their assistance in several techniques. We also thank Miguel Campanero and Yuri Chiodo (Instituto de Investigaciones Biomédicas Alberto Sols, Madrid, Spain) for their assistance with the IVIS system; Fernando González and Silvia Hernández for confocal assistance; Raquel Pérez for histology assistance; Mario Alía for Flow Cytometry assistance (Instituto de Salud Carlos III, ISCIII, Madrid, Spain); George Bell for editorial assistance; and Manuel Ramírez (Hospital Universitario Niño Jesús, Madrid, Spain) for stimulating discussion and critical assessment of the manuscript. 


\section{CONFLICTS OF INTEREST}

The authors declare that they have no conflicts of interests.

\section{FUNDING}

This work was supported by grants from the Fondo de Investigaciones Sanitarias (PI05/2217; PI08/0029; PI14CIII/00005), RTICC (RD12/0036/0015; RD12/0036/0027) and the Madrid Regional Government (S-BIO-0204-2006, MesenCAM; P2010/BMD-2420, CellCAM) in Spain to JG-C. ER and TC are supported by the "Sara Borrell" program of the Instituto de Salud Carlos III. The experiments were approved by the appropriate committees.

\section{REFERENCES}

1. Fridman WH, Pages F, Sautes-Fridman C, Galon J. The immune contexture in human tumours: impact on clinical outcome. Nat Rev Cancer. 2012; 12:298-306.

2. Pardoll DM. The blockade of immune checkpoints in cancer immunotherapy. Nat Rev Cancer. 2012; 12:252-264.

3. Russell SJ, Peng KW, Bell JC. Oncolytic virotherapy. Nat Biotechnol. 2013; 30:658-670.

4. Coffin RS. From virotherapy to oncolytic immunotherapy: where are we now? Curr Opin Virol. 2015; 13:93-100.

5. Alemany R. Viruses in cancer treatment. Clin Transl Oncol. 2013; 15:182-88.

6. Kaufmann JK, Nettelbeck DM. Virus chimeras for gene therapy, vaccination, and oncolysis: adenoviruses and beyond. Trends Mol Med. 2012; 18:365-76.

7. Shah K. Mesenchymal stem cells engineered for cancer therapy. Adv Drug Deliv Rev. 2012; 64:739-748.

8. Uchibori R, Tsukahara T, Ohmine K, Ozawa K. Cancer gene therapy using mesenchymal stem cells. Int J Hematol. 2014; 99:377-382.

9. Willmon C, Harrington $\mathrm{K}$, Kottke $\mathrm{T}$, Prestwich $\mathrm{R}$, Melcher A, Vile R. Cell carriers for oncolytic viruses: Fed Ex for cancer therapy. Mol Ther. 2009; 17:1667-1676.

10. Ahmed AU, Rolle CE, Tyler MA, Han Y, Sengupta S, Wainwright DA, Balyasnikova IV, Ulasov IV, Lesniak MS. Bone marrow mesenchymal stem cells loaded with an oncolytic adenovirus suppress the anti-adenoviral immune response in the cotton rat model. Mol Ther. 2010; 18:1846-1856.

11. Gebler A, Zabel O, Seliger B. The immunomodulatory capacity of mesenchymal stem cells. Trends Mol Med. 2012; 18:128-134.

12. Melen GJ, Franco-Luzon L, Ruano D, Gonzalez-Murillo A, Alfranca A, Casco F, Lassaletta A, Alonso M, Madero L, Alemany R, Garcia-Castro J, Ramirez M. Influence of carrier cells on the clinical outcome of children with neuroblastoma treated with high dose of oncolytic adenovirus delivered in mesenchymal stem cells. Cancer Lett. 2016; 371:161-170.
13. Chan JL, Tang KC, Patel AP, Bonilla LM, Pierobon N, Ponzio NM, Rameshwar P. Antigen-presenting property of mesenchymal stem cells occurs during a narrow window at low levels of interferon-gamma. Blood. 2006; 107:4817-4824.

14. Sonabend AM, Ulasov IV, Tyler MA, Rivera AA, Mathis JM, Lesniak MS. Mesenchymal stem cells effectively deliver an oncolytic adenovirus to intracranial glioma. Stem Cells. 2008; 26:831-841.

15. Martinez-Quintanilla J, He D, Wakimoto H, Alemany R, Shah K. Encapsulated stem cells loaded with hyaluronidaseexpressing oncolytic virus for brain tumor therapy. Mol Ther. 2015; 23:108-118.

16. Garcia-Castro J, Alemany R, Cascallo M, MartinezQuintanilla J, Arriero Mdel M, Lassaletta A, Madero L, Ramirez M. Treatment of metastatic neuroblastoma with systemic oncolytic virotherapy delivered by autologous mesenchymal stem cells: an exploratory study. Cancer Gene Ther. 2010; 17:476-483.

17. Duncan SJ, Gordon FC, Gregory DW, McPhie JL, Postlethwaite R, White R, Willcox HN. Infection of mouse liver by human adenovirus type 5. J Gen Virol. 1978; 40:45-61.

18. Starzinski-Powitz A, Schulz M, Esche H, Mukai N, Doerfler W. The adenovirus type 12 - mouse cell system: permissivity and analysis of integration patterns of viral DNA in tumor cells. EMBO J. 1982; 1:493-497.

19. Hallden G, Hill R, Wang Y, Anand A, Liu TC, Lemoine NR, Francis J, Hawkins L, Kirn D. Novel immunocompetent murine tumor models for the assessment of replicationcompetent oncolytic adenovirus efficacy. Mol Ther. 2003; $8: 412-424$

20. Woller N, Knocke S, Mundt B, Gurlevik E, Struver N, Kloos A, Boozari B, Schache P, Manns MP, Malek NP, Sparwasser T, Zender L, Wirth TC, et al. Virus-induced tumor inflammation facilitates effective DC cancer immunotherapy in a Treg-dependent manner in mice. J Clin Invest. 2011; 121:2570-82.

21. Wang Y, Hallden G, Hill R, Anand A, Liu TC, Francis J, Brooks G, Lemoine N, Kirn D. E3 gene manipulations affect oncolytic adenovirus activity in immunocompetent tumor models. Nat Biotechnol. 2003; 21:1328-1335.

22. Alonso MM, Cascallo M, Gomez-Manzano C, Jiang $\mathrm{H}$, Bekele BN, Perez-Gimenez A, Lang FF, Piao Y, Alemany R, Fueyo J. ICOVIR-5 shows E2F1 addiction and potent antiglioma effect in vivo. Cancer Res. 2007; 67:8255-8263.

23. Cascallo M, Alonso MM, Rojas JJ, Perez-Gimenez A, Fueyo J, Alemany R. Systemic toxicity-efficacy profile of ICOVIR-5, a potent and selective oncolytic adenovirus based on the pRB pathway. Mol Ther. 2007; 15:1607-1615.

24. Alemany R, Curiel DT. CAR-binding ablation does not change biodistribution and toxicity of adenoviral vectors. Gene Ther. 2001; 8:1347-1353.

25. Dmitriev I, Krasnykh V, Miller CR, Wang M, Kashentseva E, Mikheeva G, Belousova N, Curiel DT. An adenovirus vector 
with genetically modified fibers demonstrates expanded tropism via utilization of a coxsackievirus and adenovirus receptor-independent cell entry mechanism. J Virol. 1998; 72:9706-9713.

26. Mosna F, Sensebe L, Krampera M. Human bone marrow and adipose tissue mesenchymal stem cells: a user's guide. Stem Cells Dev. 2010; 19:1449-1470.

27. Yong RL, Shinojima N, Fueyo J, Gumin J, Vecil GG, Marini FC, Bogler O, Andreeff M, Lang FF. Human bone marrow-derived mesenchymal stem cells for intravascular delivery of oncolytic adenovirus Delta24-RGD to human gliomas. Cancer Res. 2009; 69:8932-8940.

28. Liu Q, White LR, Clark SA, Heffner DJ, Winston BW, Tibbles LA, Muruve DA. Akt/protein kinase B activation by adenovirus vectors contributes to NFkappaB-dependent CXCL10 expression. J Virol. 2005; 79:14507-14515.

29. Wilson AA, Kwok LW, Porter EL, Payne JG, McElroy GS, Ohle SJ, Greenhill SR, Blahna MT, Yamamoto K, Jean JC, Mizgerd JP, Kotton DN. Lentiviral delivery of RNAi for in vivo lineage-specific modulation of gene expression in mouse lung macrophages. Mol Ther. 2013; 21:825-833.

30. Blackwell TS, Christman JW. The role of nuclear factorkappa B in cytokine gene regulation. Am J Respir Cell Mol Biol. 1997; 17:3-9.

31. Liu M, Guo S, Stiles JK. The emerging role of CXCL10 in cancer (Review). Oncol Lett. 2011; 2:583-589.

32. Hendrickx R, Stichling N, Koelen J, Kuryk L, Lipiec A, Greber UF. Innate immunity to adenovirus. Hum Gene Ther. 2014; 25:265-284.

33. Borgland SL, Bowen GP, Wong NC, Libermann TA, Muruve DA. Adenovirus vector-induced expression of the C-X-C chemokine IP-10 is mediated through capsiddependent activation of NF-kappaB. J Virol. 2000; 74:3941-3947.

34. Bernardo ME, Fibbe WE. Mesenchymal stromal cells: sensors and switchers of inflammation. Cell Stem Cell. 2013; 13:392-402.

35. Tomchuck SL, Zwezdaryk KJ, Coffelt SB, Waterman RS, Danka ES, Scandurro AB. Toll-like receptors on human mesenchymal stem cells drive their migration and immunomodulating responses. Stem Cells. 2008; 26:99-107.

36. Jiang H, Clise-Dwyer K, Ruisaard KE, Fan X, Tian W, Gumin J, Lamfers ML, Kleijn A, Lang FF, Yung WK, Vence LM, Gomez-Manzano C, Fueyo J. Delta-24-RGD oncolytic adenovirus elicits anti-glioma immunity in an immunocompetent mouse model. PLoS One. 2014; 9:e97407.
37. Treacy O, Ryan AE, Heinzl T, O’Flynn L, Cregg M, Wilk M, Odoardi F, Lohan P, O'Brien T, Nosov M, Ritter T. Adenoviral transduction of mesenchymal stem cells: in vitro responses and in vivo immune responses after cell transplantation. PLoS One. 2012; 7:e42662.

38. Hamada K, Desaki J, Nakagawa K, Zhang T, Shirakawa T, Gotoh A, Tagawa M. Carrier cell-mediated delivery of a replication-competent adenovirus for cancer gene therapy. Mol Ther. 2007; 15:1121-1128.

39. Gil-Hoyos R, Miguel-Camacho J, Alemany R. Oncolytic adenovirus characterization: activity and immune responses. Methods Mol Biol. 2014; 1089:117-32.

40. Alonso MM, Gomez-Manzano C, Jiang H, Bekele NB, Piao Y, Yung WK, Alemany R, Fueyo J. Combination of the oncolytic adenovirus ICOVIR-5 with chemotherapy provides enhanced anti-glioma effect in vivo. Cancer Gene Ther. 2007; 14:756-761.

41. Rojas JJ, Guedan S, Searle PF, Martinez-Quintanilla J, GilHoyos R, Alcayaga-Miranda F, Cascallo M, Alemany R. Minimal RB-responsive E1A promoter modification to attain potency, selectivity, and transgene-arming capacity in oncolytic adenoviruses. Mol Ther. 2010; 18:1960-1971.

42. Kirby TO, Rivera A, Rein D, Wang M, Ulasov I, Breidenbach M, Kataram M, Contreras JL, Krumdieck C, Yamamoto M, Rots MG, Haisma HJ, Alvarez RD, et al. A novel ex vivo model system for evaluation of conditionally replicative adenoviruses therapeutic efficacy and toxicity. Clin Cancer Res. 2004; 10:8697-8703.

43. Paupoo AA, Zhu ZB, Wang M, Rein DT, StarzinskiPowitz A, Curiel DT. A conditionally replicative adenovirus, CRAd-S-pK7, can target endometriosis with a cell-killing effect. Hum Reprod. 2010; 25:2068-83.

44. Rincon E, Saez de Guinoa J, Gharbi SI, Sorzano CO, Carrasco YR, Merida I. Translocation dynamics of sorting nexin 27 in activated T cells. J Cell Sci. 2011; 124:776-788.

45. Lin AW, Lowe SW. Oncogenic ras activates the ARF-p53 pathway to suppress epithelial cell transformation. Proc Natl Acad Sci USA. 2001; 98:5025-5030.

46. Jefferies WA, Kolaitis G, Gabathuler R. IFN-gammainduced recognition of the antigen-processing variant CMT.64 by cytolytic T cells can be replaced by sequential addition of beta 2 microglobulin and antigenic peptides. J Immunol. 1993; 151:2974-2985.

47. Sensken SC, Nagarajan M, Bode C, Graler MH. Local inactivation of sphingosine 1-phosphate in lymph nodes induces lymphopenia. J Immunol. 2011; 186:3432-3440. 